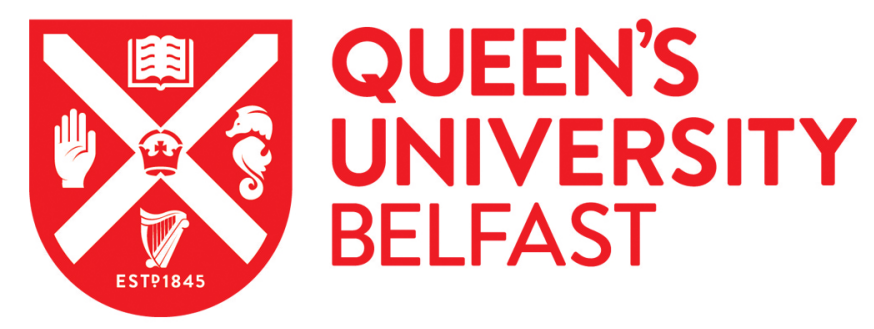

\title{
A bridge-monitoring tool based on bridge and vehicle accelerations
}

Hester, D., \& González, A. (2015). A bridge-monitoring tool based on bridge and vehicle accelerations. Structure and Infrastructure Engineering, 11(5), 619-637. https://doi.org/10.1080/15732479.2014.890631

\section{Published in:}

Structure and Infrastructure Engineering

\section{Document Version:}

Peer reviewed version

Queen's University Belfast - Research Portal:

Link to publication record in Queen's University Belfast Research Portal

\section{Publisher rights}

Copyright 2014 Taylor \& Francis.

This is an Accepted Manuscript of an article published by Taylor \& Francis in Structure and Infrastructure Engineering on 1st April 2014, available online: http://www.tandfonline.com/10.1080/15732479.2014.890631.

\section{General rights}

Copyright for the publications made accessible via the Queen's University Belfast Research Portal is retained by the author(s) and / or other copyright owners and it is a condition of accessing these publications that users recognise and abide by the legal requirements associated with these rights.

Take down policy

The Research Portal is Queen's institutional repository that provides access to Queen's research output. Every effort has been made to ensure that content in the Research Portal does not infringe any person's rights, or applicable UK laws. If you discover content in the Research Portal that you believe breaches copyright or violates any law, please contact openaccess@qub.ac.uk. 


\title{
A Bridge Monitoring Tool Based on Bridge and Vehicle Accelerations
}

\author{
David Hester ${ }^{\mathrm{a}}$ and Arturo González ${ }^{\mathrm{b}}$ \\ a SPACE, David Keir Building, Queen's University Belfast, BT9 5AG, UK \\ ${ }^{\mathrm{b}}$ School of Civil, Structural and Environmental Engineering, University College Dublin, \\ Belfield, Dublin 4, Ireland
}

\begin{abstract}
Previous research on damage detection based on the response of a structure to a moving load has reported decay in accuracy with increasing load speed. Using a 3-D vehicle-bridge interaction model, this paper shows that the area under the filtered acceleration response of the bridge increases with increasing damage, even at highway load speeds. Once a datum reading is established, the area under subsequent readings can be monitored and compared to the base line reading, if an increase is observed it may indicate the presence of damage. The sensitivity of the proposed approach to road roughness and noise is tested in several damage scenarios.

The possibility of identifying damage in the bridge, by analysing the acceleration response of the vehicle traversing it is also investigated. While vehicle acceleration is shown to be more sensitive to road roughness and noise and therefore less reliable than direct bridge measurements, damage is successfully identified in favourable scenarios.
\end{abstract}

Keywords: Bridges, Damage, Structural Health Monitoring, Dynamics, Structural Modelling, Intelligent Infrastructure

Corresponding author: David Hester

Email: d.hester@qub.ac.uk

Tel: 00442890974600

\section{Introduction}


Bridges are aging and deteriorating over time and at the same time required to carry heavier traffic loads to satisfy the increasing demand for transport capacity. When one considers that bridges form a critical link in modern transport networks, it becomes imperative to ensure their operation in safe conditions. Load and strength conditions vary with respect to the initial design stage, and it is necessary to assess if the level of risk is acceptable or not. A simple analysis can be cost effective if it demonstrates that the bridge is satisfactory, but if it does not prove the bridge is safe, the engineer should introduce more advanced assessment methods. For that purpose, the BRIME (BRIdge Management in Europe) (1999) and COST 345 (OBrien et al. 2005) European projects classify assessment in five distinct levels of sophistication. The number of model parameters increases with the level of assessment. Therefore, parameters for assessment of structural safety in lower levels of assessment can be based on visual observation, but parameters for higher levels of assessment should be estimated from load and material testing. Theoretically, the output of higher levels of assessment could be used as a diagnostic tool to prevent weaknesses at localised points and/or information on safety values.

An accurate assessment requires the calculation of the response of a mathematical model of the structure to a complete range of loading conditions. In order to represent the structural response correctly, field measurements must be taken. Forced vibration or ambient vibration dynamic tests, and testing with heavily loaded trucks can be used to determine the actual live-load behaviour of the structure, frequencies and mode shapes of vibration of a bridge. Then, model updating techniques can be employed to establish a mathematical model of the structure able to accurately predict and assess the behaviour of the structure under different static or dynamic loading conditions. Although finite element model updating techniques have been shown to provide high levels of accuracy, they rely on accurate and sufficient experimental data for model calibration which sometimes can prove to be difficult or expensive to undertake. If these data need to be gathered for many structures on a permanent basis, it will become economically unfeasible and alternative methods are required to manage large infrastructure networks (i.e., simply warning that damage may have occurred before implementing more sophisticated methods able to locate and quantify damage and predict the remaining life of the structure). With this in mind, Doebling et al. (1998) classify damage identification methods into four categories: Level I (when detecting the presence of damage in the structure, i.e., through comparison of frequencies or modes between healthy and damaged structures), Level II (= Level I plus determination of geometric location of damage, i.e., through time-frequency 
analysis methods including wavelet packet or Hilbert transforms), Level III (= Level II plus quantification of severity of damage, i.e., through stochastic subspace identification methods), and Level IV (= Level III plus prediction of remaining service life of structure).

Structural Health Monitoring (SHM) systems are currently developing very fast, and they could even replace bridge inspection and condition assessment activities for carefully selected bridges. It is suggested by Wong and Yao (2001) that SHM can be used as part of a risk management philosophy for the bridge, where SHM can provide information to understand and quantify the risk. The structure owner/operator can then use this information to select the most cost effective option for risk mitigation. Mufti et al. (2005) argue that SHM can reduce the cost of maintenance of current bridges by providing owners with information that will allow them carry out the most effective repair. The development of methods for on-line crack detection and monitoring started in the power industry in the 1970's (Dimarogonas 1996) and an historical overview of the development of SHM over the past 30 years is given by Farrar and Worden (2007). Vibration-based condition monitoring techniques, commonly used in SHM to discern information about the bridge, have been discussed in several reviews (Sohn, 2004, Carden and Fanning, 2004, Fan and Qiao, 2011, Salawu, 1997). Vibration-based methods that do not require a structural model primarily provide Level I and Level II damage identification (Doebling et al., 1998). A popular technique consists of recording the modal parameters of the structure (e.g. frequencies and mode shapes). The latter are determined by the physical properties of the structures such as stiffness mass and damping, therefore any change in the physical properties (i.e., a localised or global loss of stiffness) will cause detectable changes in the modal properties (Doebling et al., 1996). Farrar et al. (1999) provide a literature review on the different excitation methods to extract modal parameters from bridge structures. They point out that using a vehicle to excite the bridge often has the disadvantage of inducing vehicle vibrations into the bridge response but that for large bridges, ambient methods such as vehicle traffic are the only practical way to excite the bridge. Similarly, Brownjohn et al. (2003) compare three different methods of excitation of a bridge (18 m simply supported span formed using inverted $\mathrm{T}$ beams) to extract its modal parameters: shaker testing, vehicle induced response and hammer testing. The best quality data is found to be obtained from forced vibration testing with the shaker, which is capable of providing a level of excitation sufficiently high without altering the bridge frequencies. However, full scale dynamic testing using a shaker requires bridge closure and it does not allow a continuous monitoring of the bridge condition. 
As a result, monitoring of bridge vibrations induced by everyday traffic is becoming increasingly popular in SHM. Even further, some researchers have used measurements on the vehicle crossing the bridge (as opposed to direct measurements on the bridge) as an indirect mean to extract the bridge frequencies. This is driven by the very large number of bridges that are not instrumented, and therefore the need for some alternative method to monitor a change in the behaviour of the structure that might be an indicator of damage (González et al., 2010). The vehicle acts as an exciter of bridge frequencies and the vehicle receives the bridge vibrations. Theoretical investigations indicate that when monitored over a long period this information could act as a valuable reference for evaluating the degradation in stiffness or strength of the structure (Yang et al., 2004a). Experimental work by the same authors confirms the findings of their earlier theoretical study using a cart fitted with accelerometers towed behind a light commercial truck (Lin and Yang, 2005). A follow up theoretical study by the same research group examines the relative influence of the different dynamic parameters of the system on successfully identifying the bridge frequencies of concern (Yang and Chang, 2009). McGetrick et al. (2009) show that vehicle accelerations can be employed to identify not only the bridge frequencies but also changes in the structural damping.

While most of research on Level I damage identification methods based on vibrations due to traffic has focused on features extracted from frequencies and modes derived from bridge measurements (typically correlated with temperature and other environmental variables), other damage sensitive features of the bridge response have received attention (Law and Zhu, 2004). In this regard, signal processing techniques have been used to identify a localized singularity in the structural response that would not be present if the structure was healthy (Zhu and Law, 2006, Zhang et al., 2009, Hester and González, 2011). Hester and Gonzalez (2011) show that for vehicle speeds approaching highway speeds, the singularity could be hindered to an extent that would make it unidentifiable. However, even for high vehicle speeds the area under the acceleration response of a damaged structure is discernibly higher than the area under the acceleration response of a healthy structure. This paper exploits this trend to demonstrate that if a datum area is taken on the structure, subsequent areas can be used to predict if the structure has experienced damage in the interim. A key advantage of the proposed Level I damage identification method is its purely empirical nature, i.e., it does not require a mathematical model of the structure; it is simply based on the monitoring of the areas under the acceleration response at different points in time. 
The first part of the paper demonstrates how monitoring the area under the acceleration response of a bridge plate model can be used as a reliable SHM technique. The fundamental principle behind the approach can be understood by examining the example presented in Figure 1. Figure 1(a) shows two acceleration signals (' $h$ ' and 'd') plotted against the vertical axis on the left. These accelerations simulate the mid-span response of a $25 \mathrm{~m}$ span bridge to the passage of a moving 15 tonne point load travelling at $15 \mathrm{~m} / \mathrm{s}$ along the centre line of the bridge (details of the model and properties of the bridge are given in section 2 ). The ' $h$ ' plot in the figure shows the acceleration response when the bridge is healthy. The ' $d$ ' plot shows the acceleration response when there has been a uniform $20 \%$ loss of stiffness across the whole deck. At first glance, the primary differences between the healthy and damaged signals can be seen in the slightly larger amplitude and slightly longer period of the damaged signal.

Figure 1(a) also shows the filtered healthy and damaged accelerations, ' $\mathrm{hf}$ ' and ' $\mathrm{df}$ ' respectively, plotted with respect to the vertical axis on the right. The filter used here is the Moving Average Filter (MAF). In this introduction, it is sufficient to say that the MAF has the effect of removing the dynamic oscillations that are from the acceleration signal. The steep discontinuities at the ends of the filtered signals are simply the edge effects that occur when filtering a finite time series. The zone or interest for damage detection is the flat area at the centre of the filtered signals. A magnified view of this zone is given in Figure 1(b). In the latter, it can be seen that the area under the damaged filtered signal (' $\mathrm{df}$ ') is larger than the area under the healthy filtered signal (' $h \mathrm{f}$ ') between the limits $0.35 \mathrm{~s}$ and $1.3 \mathrm{~s}$. Therefore, once a datum reading is established, an increase in the area under signals recorded subsequently could be used as evidence of damage.

\section{(Approx location Figure 1)}

Section 2 describes the 3-D Vehicle-Bridge Interaction (VBI) model employed to simulate the acceleration response of a bridge traversed by a vehicle. Section 3 uses the acceleration response of the bridge to test the ability of the approach in accurately identifying and locating the transverse and longitudinal position of the damage. The influence of the distance from the sensor to the damaged location, road roughness and noise, on the accuracy of the proposed 
monitoring technique are discussed. Finally, Section 4 investigates the possibility of using vehicle measurements (instead of direct bridge measurements) as a screening tool for identifying potentially damaged bridges using the same procedure. This time, only the acceleration response of a 3-D vehicle as it traverses the bridge is employed to calculate the area used as damage indicator.

\section{Characteristics of the Simulated Response}

\subsection{Vehicle Bridge Interaction Model}

A VBI model of made up of two sub-systems, namely the moving vehicle and the bridge. Mathematically the response of each sub system is governed by the equation of motion given in Equation (1)

$$
M a(t)+C v(t)+K y(t)=f(t)
$$

where $\mathbf{y}(\mathbf{t})$ contains the displacement of the degrees-of-freedom of the model, and $\mathbf{v}(\mathbf{t})$ and $\mathbf{a}(\mathbf{t})$ their velocities and accelerations respectively. $\mathbf{M}, \mathbf{C}$ and $\mathbf{K}$ are the mass, damping and stiffness matrices of the system and $\mathbf{f}(\mathbf{t})$ is the vector of applied forces at each degree-of-freedom. The two sub-systems interact with each other via the contact forces that exist between the wheels and the bridge surface, therefore mathematically the problem is coupled and time dependant (Yang et al., 2004b). It is necessary to solve both subsystems while ensuring compatibility at the contact points (i.e., displacements of the bridge and the vehicle being the same at the contact point of the wheel with the roadway) (González, 2010). Several approaches on implementing VBI simulations are available in the literature (Green et al. 1995, Wang et al. 1996, Yang and Fonder 1996, Green and Cebon 1997, Zhu and Law 2002, Yang and Lin 1995, Henchi et al. 1998, Yang et al. 2004b, Kim et al., 2005) This paper uses the iterative approach described by Green and Cebon (Green and Cebon 1994, Green and Cebon 1997) to ensure compatibility between the two sub-systems. This approach has shown good agreement with other techniques available to model the interaction between the vehicle and the bridge (González, 2010). The Newmark- $\beta$ direct integration scheme is used to solve the vehicle system equations (Tedesco et al. 1999, Dukkipati 2009). 
The theoretical bridge model employed in the simulations is a $25 \mathrm{~m}$ long and $9 \mathrm{~m}$ wide simply supported span. The reported bridge is not a specific existent bridge. However, the properties of the bridge are chosen to be representative of bridges in service. On a modern road network concrete bridges with spans in the range 20-30 m are very common. Previous research by Gonzalez (2010) showed that simply supported concrete bridges of $20 \mathrm{~m}$ and $30 \mathrm{~m}$ span can be expected to have first natural frequencies of approximately $5.0 \mathrm{~Hz}$ and $3.3 \mathrm{~Hz}$ respectively. The bridge modeled in this investigation falls into this category with a span of $25 \mathrm{~m}$ and a first natural frequency of $4.36 \mathrm{~Hz}$ for the healthy state. The bridge's mass per meter $(14,688 \mathrm{~kg} / \mathrm{m})$, Young's modulus $\left(E=3.5 \times 10^{10} \mathrm{~N} / \mathrm{m}^{2}\right)$ and second moment of area $\left(\mathrm{I}=1.275 \mathrm{~m}^{4}\right)$ are all consistent with the properties of an in service $25 \mathrm{~m}$ span highway bridge.

The finite element model of the bridge consists of 225 rectangular, $\mathrm{C} 1$ conforming orthogonal plate elements (Rowley 2007, Cantero et al. 2011) and the model is built in Matlab (2003). The dimensions of each plate element is $1 \mathrm{~m}$ (length) x $1 \mathrm{~m}$ (width) x $1.19 \mathrm{~m}$ (depth). In addition to the healthy bridge, four different damage scenarios are modelled. In all cases the zone of the bridge affected by damage is a $2 \mathrm{~m}$ long strip between $7 \mathrm{~m}$ and $9 \mathrm{~m}$ from the left hand support as shown in Figure 2(a). In the context of this investigation, while 'part-through' damage implies that the damage affects approximately half the width of the cross-section (4 m), 'fullthrough' damage extends across the full width $(9 \mathrm{~m})$. Therefore 'part-through' and 'fullthrough' affect damaged areas of $8 \mathrm{~m}^{2}\left(2 \times 4 \mathrm{~m}^{2}\right)$ and $18 \mathrm{~m}^{2}\left(2 \times 9 \mathrm{~m}^{2}\right)$ respectively. For these damaged areas, two levels of damage severity are considered: $25 \%$ and $50 \%$ loss of stiffness with respect to the healthy elements (A 50\% loss should be assumed in those parts of the paper where severity of the damaged bridge is not specified). Here, loss of stiffness refers to loss of flexural rigidity, and it is implemented by decreasing the modulus of elasticity with respect to the assumed healthy value. Figure 2(a) shows the geometry of the bridge model as well as indicates the size and position of the damaged areas. The bridge is divided into two lanes, marked lane 1 and lane 2 in the figure, each lane being $4.5 \mathrm{~m}$ wide. In Figure 2(a), the points A to $\mathrm{F}$ mark the locations where the bridge responses are monitored in the simulation: $\mathrm{A}(6,2)$, $\mathrm{B}(12,2), \mathrm{C}(18,2), \mathrm{D}(6,7), \mathrm{E}(12,7)$ and $\mathrm{F}(18,7)$. The first frequencies of vibration associated to the five bridge models are: $4.37 \mathrm{~Hz}$ (healthy), $4.33 \mathrm{~Hz}$ (part-through with a $25 \%$ loss of stiffness), $4.29 \mathrm{~Hz}$ (full-through with a $25 \%$ loss of stiffness), $4.28 \mathrm{~Hz}$ (part-through with a $50 \%$ loss of stiffness) and $4.14 \mathrm{~Hz}$ (full-through with a $50 \%$ loss of stiffness). Damping is neglected in all simulations unless otherwise specified. In those simulations where damping is considered, this is of the Rayleigh type in accordance with Yang et al. (2004b). 
In this paper, the damaged modelled does not represent a specific physical condition. Instead the loss of stiffness is intended to represent a series of potential conditions where the structure has lost strength with respect to its original design, (e.g. a loss of section of the reinforcement bars or damage to the pre/post tensioning cables). The parameter used to quantify damage is chosen to be in line with those used in the literature when identifying damage in beams subject to a moving load. For example authors such as Zhu \& Law (2006) and Nguyen \& Tran (2010) express the severity of damage as a crack height to beam depth ratio. In both investigations, cracks as large as $50 \%$ of the depth of the section (equivalent to a $85 \%$ stiffness loss) are examined,. In this paper, stiffness losses of $25 \%$ and $50 \%$ are employed in 'part-through' and 'full-through' damage scenarios. Table 1 shows the first natural frequency of the bridge for the different damage scenarios modelled. It can seen that even when there is substantial damage in the bridge there is relatively little change in the first natural frequency as it has been pointed in the literature by other authors (Doebling et al., 1998).

\section{(Approx location Table 1)}

In all simulations, a 2-axle vehicle travels in the centre of the lane from left to right across the structure. The wheels on axle 1 are labelled $\mathrm{W} 1$ and $\mathrm{W} 3$, and the wheels on axle 2 are labelled W2 and W4 (Figure 2(a)). The vehicle model simulates the behaviour of a 2-axle truck and consists of a body mass supported on a 2-axle wheel/suspension assembly (Figure 2(b)). The model has 7 degrees of freedom, namely a vertical displacement for each of the four wheels $\left(y_{1}, y_{2}, y_{3}\right.$ and $\left.y_{4}\right)$, and the bounce $\left(y_{b}\right)$, pitch $\left(\varphi_{p}\right)$ and roll $\left(\varphi_{r}\right)$ of the body mass. The body has mass $m_{b}$ and mass moments of inertia $I_{p}$ and $I_{r}$ for pitch and roll respectively. Essentially each vehicle corner is supported on a suspension assembly that has stiffness $\mathrm{K}_{\mathrm{s}}$ and damping coefficient $\mathrm{C}_{\mathrm{s}}$. The mass of the wheel/axle assembly is $\mathrm{m}_{\mathrm{w}}$ and finally the tyre is modelled as a

spring with stiffness $\mathrm{K}_{\mathrm{s}}$. The vehicle equations are formulated following recommendations by Cantero et al. (2010). Table 2 provides the parameters of the vehicle (Cantero et al. 2011, ElMadany 1988). A typical highway speed of $25 \mathrm{~m} / \mathrm{s}$ is employed unless otherwise specified. The main vehicle frequencies are 1.67, 2.17, 2.59 and $11.7 \mathrm{~Hz}$ for bounce, pitch, roll and axle hop respectively. 


\section{(Approx location Figure 2)}

\section{(Approx location Table 2)}

A numerically generated road profile carpet is included in some of the simulations to allow for the fact that the vehicle will most likely be travelling on a bitumen based road surface material. Cebon (1999) describes how an artificial road surface topography can be generated for a specified ISO roughness/classification (Standardisation, 1995). A localised averaging of the road irregularities under the tyre is undertaken in accordance with Harris et al. (2007) to allow for the fact that the footprint of the tyre will cover about $0.24 \mathrm{~m}$ of road profile. In addition to the road surface on the bridge, an approach length of $100 \mathrm{~m}$ is included in the simulations to excite the vehicle initially. Figure 3 shows a $25 \mathrm{~m}$ length of road profile carpet that is used in later simulations. The section of carpet shown is the part on the bridge and it has a roughness coefficient of $4 \times 10^{-6} \mathrm{~m}^{3} /$ cycle.

\section{(Approx location Figure 3)}

\subsection{Simulated Responses}

Figures 4 (a) and (b) show the displacement when the vehicle is travelling at $25 \mathrm{~m} / \mathrm{s}$ on a smooth profile in lane 1 and there is 'part-through' damage. As expected, the largest displacements are observed at the sensors positioned at mid-span, i.e., sensors B and E. In all cases the sensors under lane 1 show a slightly larger displacement than the corresponding sensors under lane 2 . The latter is to be expected as the vehicle drives over the same lane where the 'part-through' damage is located. Figures 4(c) and (d) show the accelerations associated to the same locations of Figures 4(a) and (b). For all sensors there is an abrupt increase in the amplitude of the acceleration signal at 0.22 seconds, which is the instant at which the rear axle of the vehicle enters the bridge. Figure 4(e) shows the frequency content of the displacement signals shown in Figures 4(a). The section of the spectra from $0-2 \mathrm{~Hz}$ is omitted from the plot because this zone is dominated by the 'static' component of the displacement response. The amplitude due 
to the static response is an order of magnitude larger than that of the dynamic vibrations, and if it were included in the plot, the peaks due to dynamic vibrations would be dwarfed by the very large static amplitude. For all sensors, the dominant frequency of vibration is $4.278 \mathrm{~Hz}$, i.e., the first natural frequency of the bridge when there is 'part-through' damage in the deck (Table 1).

Figure 4(f) shows the frequency content of the acceleration signals shown in Figure 4(d). Similar to Figure 4(e), the dominant frequency of vibration of acceleration signals D, E and F is $4.278 \mathrm{~Hz}$. However, there is an additional peak for a frequency of $17.2 \mathrm{~Hz}$, which corresponds to the $2^{\text {nd }}$ mode of vibration. The higher modes of vibration are more evident in the acceleration signal (Figure 4(f)) than in the displacement signal (Figure 4(e)) due to the smaller influence of the frequency components associated to the static response. Similar plots to those shown in Figures 4(e) and (f) are found for the (displacement) signals shown in Figure 4(b) and the (acceleration) signals shown in Figure 4(c) respectively.

\section{(Approx location Figure 4 )}

González and Hester (2013) have shown that when a damaged bridge is traversed by a moving load, the structural response can be assumed to be made up of a number of components These components can be derived by separating the displacement signal into three components, namely 'static', 'dynamic' and 'damage'. The three components are plotted in Figure 5(a). Here the 'static' component $\left(\mathbf{y}_{1}\right)$ refers to the displacement that would be experienced at the measuring location if the load was statically applied and moved incrementally across the healthy structure. The 'damage' component ( $\left.\mathbf{y}_{\text {damage }}\right)$ is the difference between the static response of the damaged and healthy structures. It should be noted that the 'damage' component is quite small compared to the 'static' component and that the maximum value of the 'damage' component occurs when the load is, over the damaged section. The 'dynamic' component is due to the inertial and damping forces of the bridge and can be calculated by subtracting static response of the damaged structure $\left(\mathbf{y}_{2}\right)$ from the total displacement response. (Note, the displacement signals shown in Figures 4(a) \& (b) show the total displacement 
response of sensor locations A-F). The values $\mathbf{y}_{1}, \mathbf{y}_{2}$ and $\mathbf{y}_{\text {damage }}$ can be understood mathematically as shown in equations (2) - (4):

$$
\begin{gathered}
\mathbf{y}_{1}=\mathbf{k H}^{-1} \mathbf{f} \\
\mathbf{y}_{2}=\mathbf{k D}^{-1} \mathbf{f} \\
\mathbf{y d a m a g e}=\mathbf{y}_{2}-\mathbf{y}_{1}
\end{gathered}
$$

where, $\mathbf{k}_{\mathbf{H}}$ is the stiffness matrix of the healthy structure, $\mathbf{k}_{\mathbf{D}}$ is the stiffness matrix of the damaged structure and $\mathbf{f}$ is the vector of applied forces.

Figure 5(a) shows the theoretical components of the displacement signal for bridge location B (mid-span, lane 1) when the vehicle is travelling in lane 1 at $25 \mathrm{~m} / \mathrm{s}$ and there is 'part-through' damage. If the 'static', 'damage' and 'dynamic' components shown in Figure 5(a) are added together the result is the total mid-span displacement at sensor location B (previously shown in Figure 4(a)). If the 'static', 'damage' and 'dynamic' components of displacement in Figure 5(a) are differentiated twice with respect to time, it is possible to obtain the 'static', 'dynamic' and 'damaged' components of acceleration that are shown in Figure 5(b). The 'dynamic' component of acceleration is plotted with respect to the y-axis on the left side, while the 'static' and 'damage' components are plotted with respect to the y-axis on the right side. By comparing the scale of different y-axes it can be seen that the 'dynamic' component is an order of magnitude larger than the 'static' and 'damage' components. The two peaks in the 'damage' component at $0.3 \mathrm{~s}$ and $0.55 \mathrm{~s}$ are due to the front and rear axles respectively crossing the damaged portion of the bridge. The reason the second peak has a larger amplitude than the first is simply due to the fact that the rear axle is heavier than the front axle. If the components in Figure 5(b) are added together, it would be possible to obtain the acceleration response corresponding to location B in Figure 4(c).

\section{(Approx location Figure 5)}


Figure 5 shows the theoretical 'damage' component for one measurement location within the deck (location B). If the acceleration signal is obtained at a number of transverse locations corresponding to a given longitudinal section (e.g., 9 different measurement points for a section at $1 / 4$ Span), then, a theoretical 'damage' surface can be produced as depicted in Figures 6(a)(c). The damage and loading scenario in Figure 6 are the same as in Figures 4 and 5.

In Figure 6, it can be seen that regardless of the sensor location on the bridge (longitudinally or transversely), the damage is clearly identified. However, the closer the sensor to the damage (longitudinally located between 0.28 and 0.36 of the span), the larger the amplitude of the 'damage' component becomes. Therefore, if the 'dynamic' component could be safely removed from the total acceleration signal and only 'static' and 'damage' components remained, it would be possible to separate both and identify if and where damage had occurred.

\section{(Approx location Figure 6)}

Then, the objective of the damage detection algorithm becomes to remove the 'dynamic' component from the acceleration signal to expose the 'static' and if present 'damage' component. This objective is achieved using a Moving Average Filter (MAF). In effect, a MAF is a form of low pass filtering, that also has the characteristic of maintaining the area under the filtered signal, and this proves to be a useful feature for damage detection. A comprehensive description of the MAF and how it is applied is given below.

A MAF replaces each point in a signal, a(t), at an instant $t$, with the average $\bar{a}(t)$ of several adjacent points (Equation (5)) and it is employed here to remove the 'dynamic' component.

$$
\bar{a}(t)=\frac{1}{M} \sum_{j=-\frac{(M-1)}{2}}^{\frac{(M-1)}{2}} a(t+j \Delta t)
$$

where $\Delta \mathrm{t}$ is the time step between consecutive inputs and $M$ is the span of the MAF. For example if $M$ is 7 , point 20 of the filtered signal $\bar{a}(t)$ is found by calculating the average of 
points 17 to 23 of the input signal a(t). If the acceleration signals in Figure 4(c) are examined, it can be seen that a given period of vibration has an approximately equal measure of positive and negative parts. Therefore if the span of the MAF is set to equal one period of vibration, the positive and negative parts will cancel each other out and as a result most of the dynamic oscillations will be filtered out. When the vehicle is travelling at speeds close to highway speed, generally the filtering necessary to remove the 'dynamic' component also smoothes the 'damage' component. As a result, the 'damage' component may no longer be distinguishable from the 'static' component, and therefore the damage may not be located or identified easily. However, the following section shows how the 'damage' component that remains after filtering can be sufficient to identify damage.

\section{Use of Bridge Accelerations to Detect Damage}

\subsection{Using the area under filtered signals to identify damage}

While the MAF has the benefitial effect of removing the 'dynamic' component, it can also have an impact on the 'damage' component., i.e., smoothing it. The impact the MAF has on the damage component can be understood by examining Figure 7 which shows the effect of applying a MAF to the theoretical 'static' and 'damage' components. The span of the MAF is set to remove a frequency of $4.3 \mathrm{~Hz}$ (period of vibration is $0.232 \mathrm{~s}$ ), which is $1^{\text {st }}$ natural frequency of the 'part-through' damage bridge. Given that the scanning frequency is $1000 \mathrm{~Hz}$, a MAF with an $M$ value of $(1000 * 0.232=) 232$ points will remove the first natural frequency. Prior to filtering, each end of the signal is padded with a copy of itself to reduce edge effects. The 'PT before filtering' (PT implies 'part-through 'damage) plot in the figure is the sum of the 'static' and 'damage' components shown in Figure 5(b). The 'PT after filtering' plot is the result of applying the MAF to the 'PT before filtering' plot. The 'healthy after filtering' signal is obtained by applying the MAF to the 'static' component shown in Figure 5(b). The detail of the damaged location is lost in the filtering process, however, evidence of the occurance of damage remains. The area under the 'PT after filtering' signal is greater than the area under the 'healthy after filtering' signal, i.e. damage has the effect of increasing the area under the filtered signal. Figure 7 also provides a plot of the 'FT after filtering' (FT implies 'full-through' 
damage), which further illustrates how area under the filtered signal increases with more severe damage.

\section{(Approx location Figure 7)}

\subsection{Area Ratios as a Tool for Health Monitoring}

The plots in Figure 7 are obtained by filtering the theoretical components of the acceleration response to demonstrate the area under the filtered signal is related to the severity of damage. The same filtering procedure can be applied to total acceleration responses. Therefore, the 'part-through' plot in Figure 8 is the result of filtering the total acceleration response from bridge location B in Figure 4(c) with a MAF set to remove a $4.3 \mathrm{~Hz}$ frequency. (Note, as in the last section both ends of the signal were padded prior to applying the MAF).When the bridge is loaded with a 2-axle vehicle, there can be abrupt changes in the amplitude of the acceleration response as the vehicle's axles pass on and off the bridge. This phenomena can be seen in Figure 4(c) when there is an abrupt increase in the amplitude of the acceleration signal at approximately $0.22 \mathrm{~s}$. This corresponds to the time the rear axle enters the bridge $(5.5 \mathrm{~m} / 25$ $\mathrm{m} / \mathrm{s}=0.22 \mathrm{~s}$ ). It is this sudden change in amplitude that causes the trough in the filtered signal of Figure 8 at $0.2 \mathrm{~s}$. Similarily the front axle leaving the bridge at $1.0 \mathrm{~s}$ results in a trough at the right hand end of the filtered signal. As a result, only the central portion of the filtered signal away from axles entering/leaving the bridge qualifies for damage detection. The result of applying the same filtering procedure to the total accelerations simulated at location B (Figure 2(a)) for 'full-through' and 'healthy' scenarios are also shown in the figure for comparison purposes. The areas under each of the filtered signals are calculated between limits of 0.3 and 0.9 seconds, and areas of $0.00572,0.00599,0.00641 \mathrm{~m} / \mathrm{s}$ are obtained for the 'healthy', 'partthrough' and 'full-through' scenarios respectively. There is clearly an increase in the area under the filtered signal for more severe damage. Therefore if a datum reading is taken on the structure at a point in time, all subsequent readings can be compared to the original datum value. If an increase in area is observed and is consistent througout time, it may be indicative that the structure has experienced a loss of stiffness from the time the first measurement campaign took place. Rather than expressing the increase in area in absolute terms, it is more informative to provide its value relative to the datum reading. For example, an area ratio is 
defined here as the increment in total area under the acceleration curve between measurements at two points in time, $t$ and $t+\Delta t$, divided by the total area under the acceleration curve at the first time $t$. In the case of Figure 8, if the structure is assumed to be in a healthy state for the first measurements, area ratios of $0.00,0.05,0.12$ correspond to the healthy, 'part-through' and 'full-through' scenarios respectively.

To investigate if damping could have a significant effect on the performance of the algorithm, the bridge is modelled with a damping ratio of $5 \%$. Then the (damped) acceleration signals simulated at location B for 'healthy', 'part-through' and 'full-through' scenarios are analysed leading to the results shown in Figure 8(b). It can be seen that the plots in part (b) of the figure are very similar to the corresponding plots in part (a). When the areas under each of the filtered signals of Figure 8(b) are calculated between limits of 0.3 and 0.9 seconds, areas of 0.00570 , $0.00597,0.00636 \mathrm{~m} / \mathrm{s}$ are obtained for the 'healthy', 'part-through' and 'full-through' scenarios respectively. These areas produce area ratios of $0.00,0.05,0.12$ for 'healthy', 'part-through' and 'full-through' respectively, which are the same values observed for $0 \%$ damping ratio, i.e., the algorithm does not appear to be particularly sensitive to damping.

\section{(Approx location Figure 8)}

\subsection{Influence of Sensor Location, Travelling Lane and Road Roughness on Area Ratios}

All three plots in Figure 8 are obtained by filtering accelerations simulated at location B (lane 1, midspan) when the vehicle is travelling over a smooth surface in lane 1 . To investigate if a similar increase in area could be detected at other sensor locations and/or vehicle positions on a rough surface, the result of processing a series of simulations with the vehicle travelling in both lanes over different road profiles is illustrated in Figure 9 for sensor locations A (lane 1, 1/4 span), E (lane 2, mid-span) and C ( lane 1, 3/4 span). Each road profile is generated randomly according to Section 2.1. The roughness coefficients of the road profile range from 4 to $32 \times 10^{-6} \mathrm{~m}^{3} /$ cycle, covering class 'A' (very good) and class 'B' (good) ISO profiles (Standardisation, 1995) most likely to be found on modern highways. Results for a smooth profile (roughness coefficient $=0$ ) are also included for comparison purposes. For all 
simulations, responses from the healthy structure are used as the datum readings in the calculation of area ratios.

The data points represented in Figure 9(a) are obtained by applying the procedure given in section 3.1 to the accelerations of bridge location A. Firstly it can be seen that there is a clear increase in the area ratio from the datum to 'part-through' and on to 'full-through' damage. While there is some variation in the value of the area ratio for different roughness coefficients, it must be noted this variation is quite small across the range of roughness coefficients modelled, thereby showing that the method is not particularly sensitive to road profile for this VBI scenario. When there is 'part-through' damage in the structure, the area ratio observed when the vehicle is in lane 1 is slightly higher than the ratio observed when the vehicle is in lane 2. This is not entirely surprising considering that the 'part-through' damage is under lane 1 so a slightly higher ratio is observed when the vehicle is in this lane. When there is 'fullthrough' damage the ratio observed is similar irrespective of which lane the vehicle travels in.

Data points represented in Figure 9(b) correspond to the accelerations simulated at sensor location $\mathrm{E}$, and similar to location $\mathrm{A}$, they show a clear increase in the area ratio as the severity of damage increases. For a given damage level, the ratios, although slightly smaller than those observed in Figure 9(a) (given that sensor A is closer to the damage), also remain relatively consistent across a range of road profiles. For example, the average area ratios (across all road profiles) for 'full through' damage are 0.163 (location A) and 0.131 (location E). The average area ratios (across all road profiles) for 'part through' damage are 0.064 (location A) and 0.045 (location $\mathrm{E}$ ). The difference in area ratio between bridge locations $\mathrm{A}$ and $\mathrm{E}$ can be understood by the fact that the sensor $\mathrm{A}$ is $2 \mathrm{~m}$ from the centre of the damaged zone whereas sensor $\mathrm{E}$ is 4 $\mathrm{m}$ from the centre of the damaged zone (see Figure 2(a)). Figure 9(c) shows the results for sensor location $\mathrm{C}$, located at $10 \mathrm{~m}$ from the center of the damaged zone. Consequently the area ratios observed at this location are significantly lower than those observed at locations $\mathrm{A}$ and $\mathrm{E}$ and therefore are less sensitive to an increase in damage.

\section{(Approx location Figure 9)}

\subsection{Use of Multiple Sensors to Locate Damage}


From Figure 9, it is clear that using one sensor location could be sufficient to tell if the structure has experienced a loss of stiffness, however it would give no information on its location. If three sensor locations are used, it can be discerned that the damage will be located in the first half of the span based on the area ratios from each location. However, if more sensors are used, it is likely that the damage will be located more accurately. Twenty sensors (5 longitudinally and 4 transversely) are used to test this hypothesis. Longitudinaly the sensors are numbered 15 and transversely they are labelled Q-T. The coordinates of sensors Q1 to Q5 are $(4,2),(8,2)$, $(12,2),(16,2)$ and $(20,2)$ respectively. Sensors R1 to R5 have coordinates $(4,4),(8,4),(12,4)$, $(16,4)$ and $(20,4)$. Sensors S1 to S5 have coordinates $(4,5),(8,5),(12,5),(16,5)$ and $(20,5)$. Sensors T1 to T5 have coordinates $(4,7),(8,7),(12,7),(16,7)$ and $(20,7)$.

A class ' $A$ ' road profile with roughness coefficient of $4 \times 10^{-6} \mathrm{~m}^{3} /$ cycle is employed in the simulations. Figures 10 and 11 show the results when the affected elements have experienced a 50\% loss of stiffness. Figures. 10(a) and (b) show the area ratios obtained for the vehicle travelling at $25 \mathrm{~m} / \mathrm{s}$ in lane 1 for a bridge with 'part through' and 'full through' damage respectively. While the horizontal axes in the figure show the longitudinal and transverse position of the sensors, the vertical axis indicates the area ratio calculated at each sensor location. When there is part through damage in the bridge (Figure 10(a)) it is noticeable that the area ratio is greater than zero in every sensor so all the sensors are detecting the damage. However, the area ratios calculated for sensors in the first half of the bridge span (where damage is) are clearly higher than those in the second half of the span. On closer inspection it can be seen that the largest area ratio occurs at sensor location Q2 (coordinates $x=8, y=2$ ), the closest sensor to the damage (defined by the zone $7<x<9,0<y<4$ ).

\section{(Approx location Figure 10)}

Figure 11(a) shows the area ratios corresponding to the vehicle travelling in lane 2 of a bridge with a 'part through' damage. Again the largest area ratio occurs at sensor location Q2 which is closest to the damage. The surface of area ratios for a 'full-through' damage scenario is shown in Figures 10(b) and 11(b) for the vehicle travelling in lane 1 and lane 2 respectively. Similar to the situation for 'part-through' damage, all sensor locations exhibit area ratios greater than zero, however the magnitude of the area ratios are significantly larger than those observed for 'part through' damage. In Figures 10(b) and 11(b), the largest area ratios occur at 
sensor locations Q2, R2, S2 and T2, $8 \mathrm{~m}$ being the $x$-coordinate of all of these sensors. These are the sensors with a closer longitudinal coordinate to that of damage, which covers a zone between $x=7 \mathrm{~m}$ and $x=9 \mathrm{~m}$. For the isotropic bridge under investigation, Figuress 10 and 11 have shown that the accuracy of the determination of the damaged zone is related to the number of available measurement locations and relatively irrespective of the lane crossed by the vehicle.

\section{(Approx location Figure 11)}

Figure 12 shows the performance of the algorithm when the damaged elements are modelled as having a $25 \%$ loss of stiffness and the vehicle travels in lane 1. Parts (a) and (b) of the figure show the results of the algorithm for 'part-through' and 'full-through' damage respectively. The pattern in Figure 12 is very similar to that observed in Figure 10 in that the area ratios observed at all sensor locations is greater than zero, so the damage is being picked up at all sensors. However, in all cases the area ratios are lower than the corresponding area ratios in Figure 10. This is simply due to the fact that the severity of damage is less in Figure 12 (25\% stiffness loss) than in Figure 10 (50\% stiffness loss). Figure 12(a) shows the results for "partthrough' damage and sensor Q2 shows the largest value of area ratio. This is because it is the sensor location closest to the location of damage. Figure 12(b) shows the results observed when there was 'full-through' damage in the bridge. The sensors closest to the damage namely, Q2, $\mathrm{R} 2$, S2 and T2 show the largest value of area ratio. This is the same pattern as was observed in Figures 10 and 11.

\section{(Approx location Figure 12)}

\subsection{Influence of Noise on Area Ratios}

It is acknowledged that measurements recorded in the field will contain noise. However, it is difficult to evaluate and simulate the many possible 'pollution' sources on site. In this paper, the level of noise is initially set at $3 \%$. The decision to employ a $3 \%$ noise is based on a true measured noisy acceleration signal shown in Figure 13. This acceleration has been gathered from a QA700 accelerometer at rest. It can be seen how the measured signal varies about a mean by $\pm 0.005 \mathrm{~m} / \mathrm{s}^{2}$. Figure 4 shows simulated total accelerations of $\pm 0.2 \mathrm{~m} / \mathrm{s}^{2}$ and higher. I.e., the recorded noise level below represents a Signal to Noise ratio of about 0.2/0.005 $=40$, 
and a relative error in the measurements of $1 / 40=2.5 \%$. For this reason, a noise percentage of $3 \%$ has been used in the simulations.

\section{(Approx location Figure 13)}

Figures 14 (vehicle on lane 1) and 15 (vehicle on lane 2) carry out the same analysis as in Figures 10 and 11, except that this time 3\% noise has been added to the theoretical acceleration response to simulate a corrupted signal. Noise is added here to the simulated acceleration using the additive model of Equation (6) (Zhu and Law, 2006).

$$
\left\{a_{\text {corrupted }}(t)\right\}=\{a(t)\}+\mathrm{E}_{\mathrm{p}}\{\mathrm{N}\} \sigma
$$

where $\left\{a_{\text {corrupted }}(t)\right\}$ is a vector of corrupted accelerations, $\{a(t)\}$ is a vector of noise-free accelerations, $E_{p}$ is the noise level (3\% in this case), $\{\mathrm{N}\}$ is a standard normal distribution vector with zero mean value and unit standard deviation, and $\sigma$ is the standard deviation of the noise-free accelerations.

\section{(Approx location Figure 14 )}

\section{(Approx location Figure 15)}

The overall shapes of the surfaces in Figures 14 and 15 are similar to those seen in Figures 10 and 11 respectively and damage can still be identified. However, noise has the effect of producing surfaces that are less smooth than in the noise-free case, i.e., there is less consistency between area ratios calculated at adjacent sensors. The source of this inconsistency can be understood by examining Figure 16 representing the areas calculated from both noise-free accelerations and those containing 3\% noise at sensor locations Q1 to Q5 for the vehicle travelling in lane 1 . The small data markers in the figure represent areas calculated from noisefree accelerations, and the large symbols represent areas calculated from corrupted accelerations. When 'full-through' damage is simulated, the area calculated from noise-free 
and corrupted accelerations are almost the same for the sensor Q1, but for other sensors as Q3, the area under the noisy acceleration may differ from the noise-free value. Nevertheless, for the level of noise considered here, the noise randomness is not sufficient to misinterpret the 'full-through' or 'part-through' damage scenarios, i.e., highest areas will still be found for the most severe of the two scenarios and at the sensors that are closest to the damaged zone.

\section{(Approx location Figure 16)}

To further investigate the impact of noise on the performance of the algorithm, simulations where the acceleration signals input to the algorithm contain 5\% noise were undertaken. It was found that the addition of 5\% noise had the effect of producing a surface that was less smooth than when the noise level is $3 \%$, however, damage could still be identified. The increased inconsistency between adjacent sensors when noise is 5\% (as opposed to 3\%) is not unexpected following the observations made in Figure 16.

\section{Use of Vehicle Accelerations to Detect Damage}

The previous section has shown that for a given measurement location and test vehicle, the area under the filtered acceleration of a damaged bridge is larger than the area under the filtered acceleration of a healthy bridge. The origin of the additional area under the damaged acceleration response can be traced back to the additional static displacement experienced at the measurement location due to the damage. Unlike bridge accelerations which are recorded at one single location, vehicle accelerations are obtained at different positions on the bridge. However, due to the interaction between both structural systems, it is expected that the vehicle will also experience a certain amount of additional displacement when crossing a damaged bridge compared to a healthy one. Figure 17 shows the total displacement of wheel W1 on the front axle (Figure 2(a) shows the position of W1) for 'healthy' and 'full-through' damage scenarios when the vehicle is travelling at $25 \mathrm{~m} / \mathrm{s}$ on a smooth surface in lane 1 . This 
displacement corresponds to the degree of freedom of the vehicle above the tyre spring ( $y_{1}$ in Figure 2(b)), i.e., simulating the response of an accelerometer mounted in the connection of the wheel to the axle. It can be seen that when there is 'full-through' damage, the total displacement of $\mathrm{W} 1$ is larger than when the bridge is healthy.

\section{(Approx location Figure 17 )}

To investigate if the same phenomena of increase in underlying area with damage observed with bridge acceleration is applicable to vehicle accelerations, a similar filtering process is carried out to reduce the 'dynamic' components of the acceleration signal and (if present) expose the 'damage' component of the response. For that purpose, it is necessary to know the frequency content of the acceleration. Figure 18 shows the Power Spectral Density (PSD) observed after carrying out a fast Fourier transform on the acceleration responses of W1 corresponding to the healthy and damaged scenarios presented in Figure 17. Substantial frequency contributions are observed at $0.96,4.47$ and $16.92 \mathrm{~Hz}$, where the last two are associated to the first and second modes of vibration of the bridge.

\section{(Approx location Figure 18 )}

As before, either end of the acceleration responses are padded and then, two MAFs are used to remove the vibrations at 16.9 and $4.47 \mathrm{~Hz}$. The result of this filtering is shown in Figure 19(a). There are some remaining oscillations in the acceleration after the bridge frequencies have been removed. To examine further the origin of the oscillation remaining in the signal after the bridge frequencies have been removed and to examine if they are affected by the speed of the vehicle the crossing of the same vehicle over the bridge is simulated at a speed of $13 \mathrm{~m} / \mathrm{s}$. The results for wheel W1 are shown in Figure 19(b), i.e. the result of filtering out the bridge frequencies. By comparing Figures (a) and (b), it can be seen that the shape of the signal remaining after removing the bridge frequencies is similar in for both speeds however, the signal remaining when the speed is $13 \mathrm{~m} / \mathrm{s}$ is almost twice as long in the time domain. There is clearly a larger content of low frequencies (i.e., induced by the static bridge displacement under 
the wheels) in the acceleration response at a speed of $13 \mathrm{~m} / \mathrm{s}$, than when the speed is $25 \mathrm{~m} / \mathrm{s}$ because the vehicle takes longer to cross the bridge. As well as being longer in the time domain, the amplitude of the signal at $13 \mathrm{~m} / \mathrm{s}$ is lower than the amplitude of the signal in Figure 19(a). This is due to the fact that for lower vehicle speeds, the 'static' component of wheel displacement changes more slowly with respect to time, and as a result, the amplitude of the 'static' component of wheel acceleration will also be smaller. Although 'full-through' signals in Figure 19 contain a 'damage' component, most of their amplitude is derived from the 'static' component.

\section{(Approx location Figure 19)}

The $0.96 \mathrm{~Hz}$ frequency component of the signal in Figure 19(a) is removed using a third MAF. Prior to the application of this filter, both ends of the accelerations in Figure 19(a) are padded with copies of themselves to avoid edge effects. The result of filtering the healthy and 'fullthrough' signals depicted in Figure 19(a) is shown in Figure 20(a). The figure also shows the effect of filtering the acceleration of wheel 1 for the case of 'part-through' damage in the bridge, and it can be seen that the amplitude of the filtered acceleration increases with increasing damage. Figure 20(b) shows the result of applying the same procedure to the case of the vehicle travelling at $13 \mathrm{~m} / \mathrm{s}$. The moving average filter used in this case was set to remove a frequency of $0.6 \mathrm{~Hz}$ to allow for the lower vehicle speed and again it can be seen that the amplitude of the filtered acceleration signal increases with increasing damage. In effect damage causes the filtered acceleration signal to shift upward, therefore if the area between successive signals is zero, it indicates that the bridge has experienced no stiffness loss since the previous reading was taken. However, a significant difference in underlying areas between successive signals may be an indicator that some damage has occurred to the bridge since the previous reading was recorded.

\section{(Approx location Figure 20)}

To investigate if the approach was sensitive to road roughness a number of simulations using different road profiles were carried out. For all simulations the vehicle is modelled as travelling in lane 1 at a speed of $25 \mathrm{~m} / \mathrm{s}$. When a rough profile is included, the vehicle frequencies become 
excited to a larger extent than in a smooth profile, and additional MAFs are necessary to remove the vehicle dynamics from the axle acceleration. In particular, two additional filters have been employed to remove frequencies of $2.5 \mathrm{~Hz}$ and $1.6 \mathrm{~Hz}$ which correspond to the vehicle bounce and roll frequencies respectively. The axle acceleration response also contains a significant amount of vibration due to axle hop $(11.7 \mathrm{~Hz})$. However, a specific filter is not required for this frequency since it is found that other filters designed to remove lower frequency components (i.e., the first bridge frequency and the vehicle bounce and roll frequencies) adequately remove the contribution of axle hop from axle acceleration signals.

Figure 21 shows the area observed between the healthy and damaged signals for each of the 4 wheels for a range of road profiles. Part (a) of the figure shows the results for wheels 1 and 2 which are on the right hand side of the vehicle, part (b) of the figure shows the results for wheels 3 and 4 on the left hand side of the vehicle (see Figure 2). Even for 'part-through' damage the approach is able to identify the presence of an area between the healthy and damaged signals. It can be seen that there is a clear increase in the area for the 'full-through' damage compared to the 'part through' damage and this increase can be observed in all 4 wheels. For all road profiles, axle accelerations at wheels 2 and 4 show a slightly greater increase than wheels 1 and 3, which is believed to be due to the fact that wheels 2 and 4 are on the heavier rear axle. The approach was found not to be particularly sensitive to road profile, i.e. for all road profiles damage was detected, and full through damage always showed a greater area than part through damage. However, as the roughness coefficient of the road profile increases the results became less consistent, in particular for roughness coefficients greater than $1.6 \times 10^{-5} \mathrm{~m}^{3} /$ cycle, greater variation becomes more evident. Figure 21 illustrates that the area between successive filtered acceleration curves could potentially be used as a simple and easyto-implement damage indicator.

\section{(Approx location Figure 21 )}

To investigate the effect of noise on the approach, $1 \%$ noise is added to each of the 4 wheel acceleration signals, noise is added as in section 3.5. The areas between healthy and damaged signals for each wheel were calculated in the same manner as previously. However, to improve robustness to noise the average from the 4 wheels was calculated and the result is presented in 
Figure 22. The results for the smooth profile in Figure 22 (roughness coefficient=0) are similar to the results observed for the smooth profile in Figure 21, so noise does not have a significant impact when the vehicle is travelling on a smooth profile. However, for all other road profiles the additive noise model employed here results in a deterioration of the performance of the technique. The reason for this is that when there is a road profile on the bridge the amplitude of the axle accelerations are far larger than when there is a smooth profile and because noise is essentially added in proportion to the standard deviation of the original signal, it becomes more significant compared to the contribution of the 'damage' component to the response. In the presence of noise, the approach still gives reasonable levels of performance on well-maintained highway profiles (roughness coefficient $<1.6 \times 10^{-5} \mathrm{~m}^{3} /$ cycle), where differences in area between healthy and damaged signals are clearly identified and 'full-through' damage shows a greater area than 'part-through' damage. However, there can be isolated cases (i.e., roughness coefficient of $2 \times 10^{-5}$ in the figure) where the combination of noise and a relatively rough road surface make the results unreliable.

\section{(Approx location Figure 22)}

Vehicle accelerations are obviously not as sensitive to bridge damage as direct acceleration measurements on the bridge. As might be expected, it is found that vehicle accelerations obtained in relatively high roughness scenarios corrupted with noise, the approach may be inaccurate. However initial findings are sufficiently positive to merit further investigations on the use of vehicle accelerations as a pre-screening tool for the efficient monitoring of large bridge networks.

\section{Conclusions}

Past research has reported on the difficulties of using the structural response to a high-speed moving load for damage detection purposes. Using a 3-D VBI model, this paper has shown that the area under the filtered acceleration response of the bridge is effective at identifying damage even at a typical highway speed. If this area is initially measured at a specific point in time, then areas and area ratios with respect to that initial area can be obtained in successive measurement campaigns to evaluate the possibility of damage occurring from the time the first datum reading was taken. One sensor may be sufficient to identify the occurrence of damage, although as the number of sensors is increased, the location of the damage can be provided 
more accurately and more reliably in the presence of noise. The proposed approach has shown low sensitivity to a range of road profiles with different roughness coefficients for the damage scenarios under investigation. Damage has also been accurately identified when adding 3\% noise to the acceleration response of the bridge. A preliminary analysis has been carried out to check the validity of applying the same procedure to the accelerations from a vehicle crossing the bridge as opposed to direct measurements from bridge locations. Although further investigations on the reliability of using a vehicle or traffic fleet for the purpose of bridge monitoring are necessary, early results are encouraging and have shown a relationship between the area between successive filtered accelerations and the severity of damage.

\section{Acknowledgements}

The authors wish to express their gratitude for the support received from the $7^{\text {th }}$ European Framework Project ASSET towards this investigation.

\section{References}

BRIDGE MANAGEMENT IN EUROPE. 1999. Experimental Assessment Methods and Use of Reliability Techniques. Final Report of the European Commission 4th Framework Programme. BRIME Deliverables D6, available at ,http://www.trl.co.uk/brime/deliver.htm.

BROWNJOHN, J. M. W., MOYO, P., OMENZETTER, P. \& LU, Y. 2003. Assessment of highway bridge upgrading by dynamic testing and finite-element model updating. Journal of Bridge Engineering, 8, 162-172.

CANTERO, D., GONZÁlEZ, A. \& O'BRIEN, E. J. 2011. Comparison of bridge dynamic amplification due to articulated 5-axle trucks and large cranes. Baltic Journal of Road and Bridge Engineering, 6, 39-47.

CANTERO, D., O'BRIEN, E. J. \& GONZÁLEZ, A. 2010. Modelling the vehicle in vehicleinfrastructure dynamic interaction studies. Proceedings of the Institution of Mechanical Engineers, Part K: Journal of Multi-body Dynamics, 224, 243-248.

CARDEN, E. P. \& FANNING, P. 2004. Vibration based condition monitoring: a review. Structural Health Monitoring, 3, 355-377.

CEBON, D. 1999. Handbook of vehicle-road interaction, Netherlands, Swets \& Zeitlinger.

DIMAROGONAS, A. D. 1996. Vibration of cracked structures: a state of the art review. Engineering Fracture Mechanics, 55, 831-857.

DOEBLING, S. W., FARRAR, C. R., PRIME, M. B. \& SHEVITZ, D. W. 1996. Damage identification and health monitoring of structural and mechanical systems from changes in their vibration characteristics: a literature review. Los Alamos National Lab., NM (United States). 
DOEBLING, S. W., FARRAR, C. R. \& PRIME, M. B. 1998. A summary review of vibrationbased damage identification methods. The Shock and Vibration Digest, 30, 91-105.

DUKKIPATI, R. V. 2009. MATLAB for Mechanical Engineers, New Age Science.

EL-MADANY, M. M. 1988. Design and optimization of truck suspensions using covariance analysis. Computers \& structures, 28, 241-246.

FAN, W. \& QIAO, P. 2011. Vibration-based damage identification methods: a review and comparative study. Structural Health Monitoring, 10, 83-111.

FARRAR, C. R., DUFFEY, T., CORNWELL, P. J. \& DOEBLING, S. W. Excitation methods for bridge structures. 17th International Modal Analysis Conference February 1999 Kissimmee, Florida Citeseer, 1063-1068.

FARRAR, C. R. \& WORDEN, K. 2007. An introduction to structural health monitoring. Philosophical Transactions of the Royal Society A: Mathematical, Physical and Engineering Sciences, 365, 303-315.

GONZÁLEZ, A. 2010. Vehicle-bridge dynamic interaction using finite element modelling. In: MORATAL, D. (ed.) Finite Element Analysis. Croatia: Sciyo.

GONZALEZ, A. \& HESTER, D. 2013. An Investigation Into The Acceleration Response of a Damaged Beam-Type Structure to a Moving Force. Journal of Sound and Vibration, 332, 3201-3217.

GONZÁleZ, A., MCGETRICK, P. J. \& O'BRIEN, E. J. Detection of Bridge Dynamic Parameters Using an Instrumented Vehicle. In: 34, P., ed. Proceedings of the Fifth World Conference on Structural Control and Monitoring, 5WCSCM, 2010 Tokyo, Japan.

GREEN, M., CEBON, D. \& COLE, D. 1995. Effects of Vehicle Suspension Design on Dynamics of Highway Bridges. Journal of Structural Engineering, 121, 272-282.

GREEN, M. F. \& CEBON, D. 1994. Dynamic response of highway bridges to heavy vehicle loads: theory and experimental validation. Journal of Sound and Vibration, 170, 51-78.

GREEN, M. F. \& CEBON, D. 1997. Dynamic interaction between heavy vehicles and highway bridges. Computers \& structures, 62, 253-264.

HARRIS, N. K., O'BRIEN, E. J. \& GONZÁLEZ, A. 2007. Reduction of bridge dynamic amplification through adjustment of vehicle suspension damping. Journal of Sound and Vibration, 302, 471-485.

HENCHI, K., FAFARD, M., TALBOT, M. \& DHATT, G. 1998. AN EFFICIENT ALGORITHM FOR DYNAMIC ANALYSIS OF BRIDGES UNDER MOVING VEHICLES USING A COUPLED MODAL AND PHYSICAL COMPONENTS APPROACH. Journal of Sound and Vibration, 212, 663-683.

HESTER, D. \& GONZÁLEZ, A. 2011. A wavelet-based damage detection algorithm based on bridge acceleration response to a vehicle. Mechanical Systems and Signal Processing, $28,21$.

KIM, C. W., KAWATANI, M. \& KIM, K. B. 2005. Three-dimensional dynamic analysis for bridge-vehicle interaction with roadway roughness. Computers \& Structures, 83, 1627 1645.

LAW, S. \& ZHU, X. 2004. Dynamic behavior of damaged concrete bridge structures under moving vehicular loads. Engineering Structures, 26, 1279-1293.

LIN, C. W. \& YANG, Y. B. 2005. Use of a passing vehicle to scan the fundamental bridge frequencies: An experimental verification. Engineering Structures, 27, 1865-1878.

MCGETRICK, P. J., GONZLEZ, A. \& O'BRIEN, E. J. 2009. Theoretical investigation of the use of a moving vehicle to identify bridge dynamic parameters. Insight-NonDestructive Testing and Condition Monitoring, 51, 433-438. 
MUFTI, A., BAKHT, B., TADROS, G., HOROSKO, A. \& SPARKS, G. 2005. Are Civil Structural Engineers "Risk Averse"? Can Civionics Help? Sensing issues in civil structural health monitoring, 3-12.

NGUYEN, K.V. \& TRAN, H.T. 2010. Multi crack detection of a beam like structure based on the vehicle vibration signal and wavelet analysis. Journal of Sound and Vibration, 329, 4455-4465.

O'BRIEN, E.J., ZNIDARIC, A., BRADY, K., GONZALEZ, A. \& O'CONNOR, A. 2005. Procedures for the assessment of highway structures. Proceedings of the Institution of Civil Engineers - Transport, 158 (1), 17-25.

ROWLEY, C. W. 2007. Moving force identification of axel forces on bridges. PhD, University College Dublin, Ireland.

SALAWU, O. 1997. Detection of Structural Damage Through Change in Frequency: A review. Engineering Structures, 19, 718-723.

SOHN, H. 2004. A review of structural health monitoring literature: 1996-2001, New Mexico, Los Alamos National Laboratory.

STANDARDISATION, I. O. F. 1995. Mechnical vibration-road surface profiles - reporting of Measure data (ISO 8608 (BS7853:1996)).

TEDESCO, J. W., MCDOUGAL, W. G. \& ROSS, C. A. 1999. Structural dynamics: theory and applications., California, USA, Addison Wesley Longman, Inc.

WANG, T.-L., HUANG, D., SHAHAWY, M. \& HUANG, K. 1996. Dynamic response of highway girder bridges. Computers \& Structures, 60, 1021-1027.

WONG, F. S. \& YAO, J. T. P. 2001. Health monitoring and structural reliability as a value chain. Computer-Aided Civil and Infrastructure Engineering, 16, 71-78.

YANG, F. \& FONDER, G. A. 1996. An iterative solution method for dynamic response of bridge-vehicles systems. Earthquake engineering \& structural dynamics, 25, 195-215.

YANG, Y. \& CHANG, K. 2009. Extracting the bridge frequencies indirectly from a passing vehicle: Parametric study. Engineering Structures, 31, 2448-2459.

YANG, Y. \& LIN, B. 1995. Vehicle-Bridge Interaction Analysis by Dynamic Condensation Method. Journal of Structural Engineering, 121, 1636-1643.

YANG, Y. B., LIN, C. W. \& YAU, J. D. 2004a. Extracting bridge frequencies from the dynamic response of a passing vehicle. Journal of Sound and Vibration, 272, 471-493.

YANG, Y. B., YAU, J. D. \& WU, Y. S. 2004b. Vehicle-bridge interaction dynamics: with applications to high-speed railways, World Scientific Pub Co Inc.

ZHANG, W. W., WANG, Z. H. \& MA, H. W. 2009. Studies on Wavelet Packet-Based Crack Detection for a Beam under the Moving Load. Key Engineering Materials, 413, 285 290.

ZHU, X. Q. \& LAW, S. S. 2002. DYNAMIC LOAD ON CONTINUOUS MULTI-LANE BRIDGE DECK FROM MOVING VEHICLES. Journal of Sound and Vibration, 251, 697-716.

ZHU, X. Q. \& LAW, S. S. 2006. Wavelet-based crack identification of bridge beam from operational deflection time history. International Journal of Solids and Structures, 43, 2299-2317. 


\section{Figures}
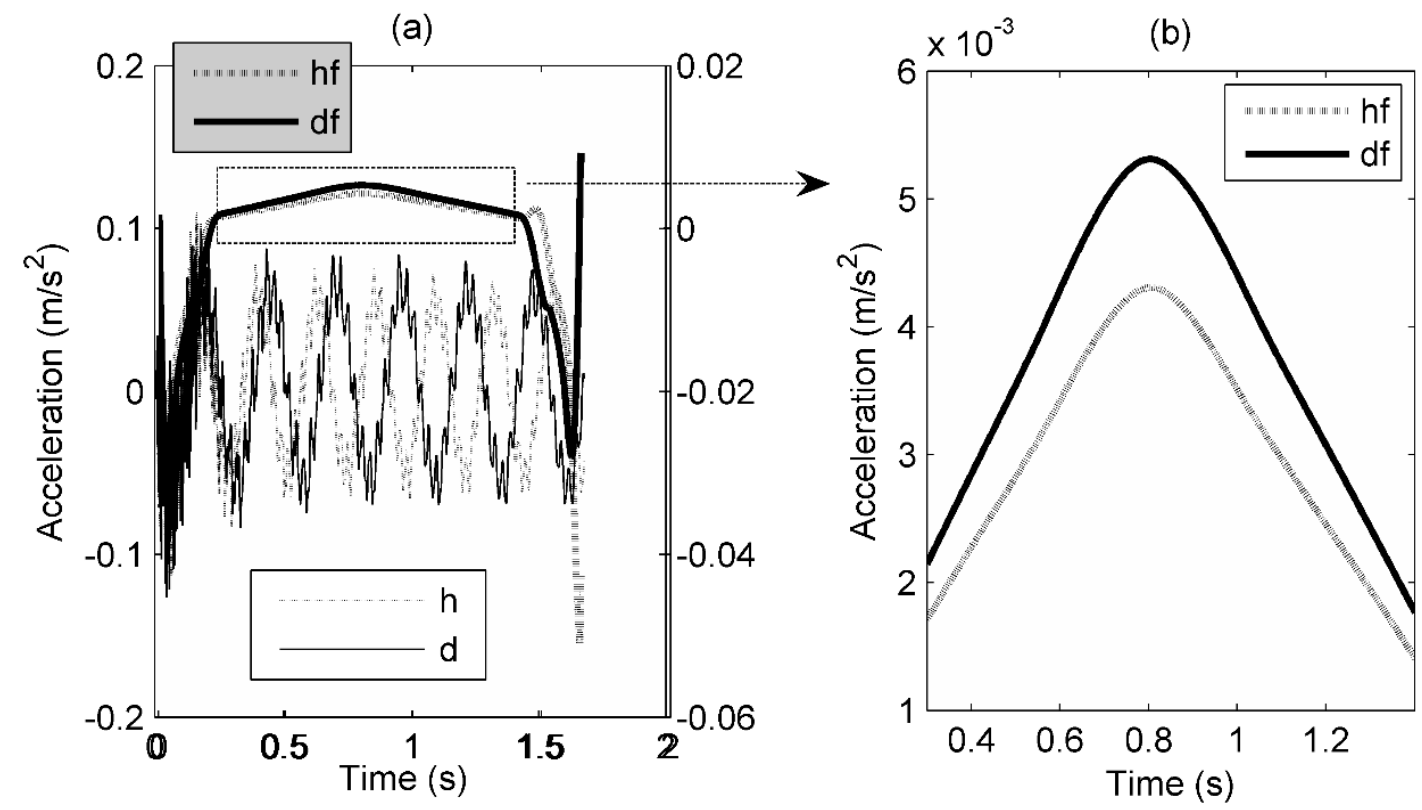

Figure 1. Acceleration signals for healthy and damaged bridge: (a) total acceleration signals and filtered acceleration signals (b), central zone of filtered signals. 


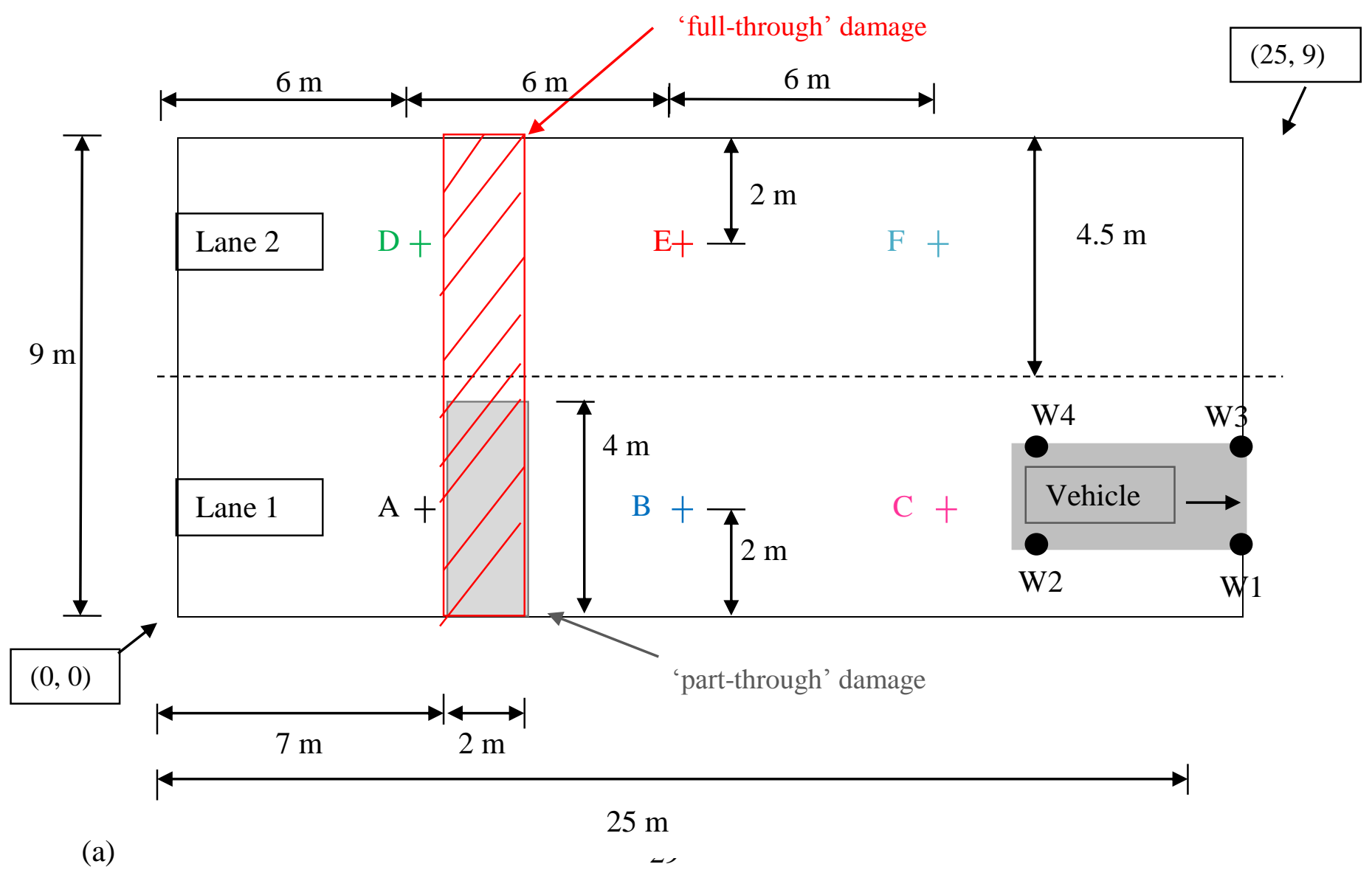




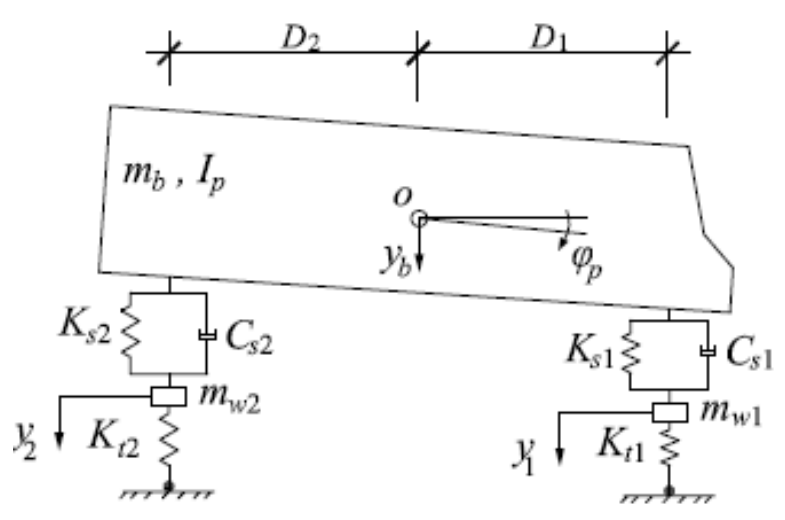

Lateral View

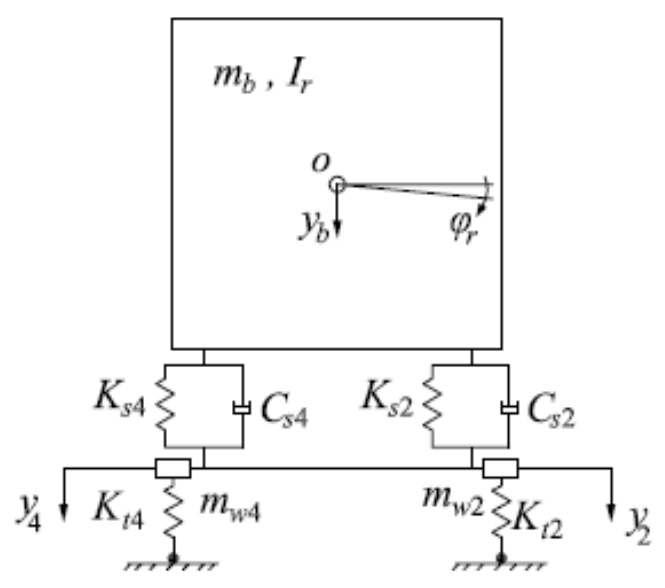

End View

(b)

Figure 2. Bridge and vehicle subsystems: (a) plan view of bridge showing the elements affected by damage, (b) vehicle model showing degrees of freedom.

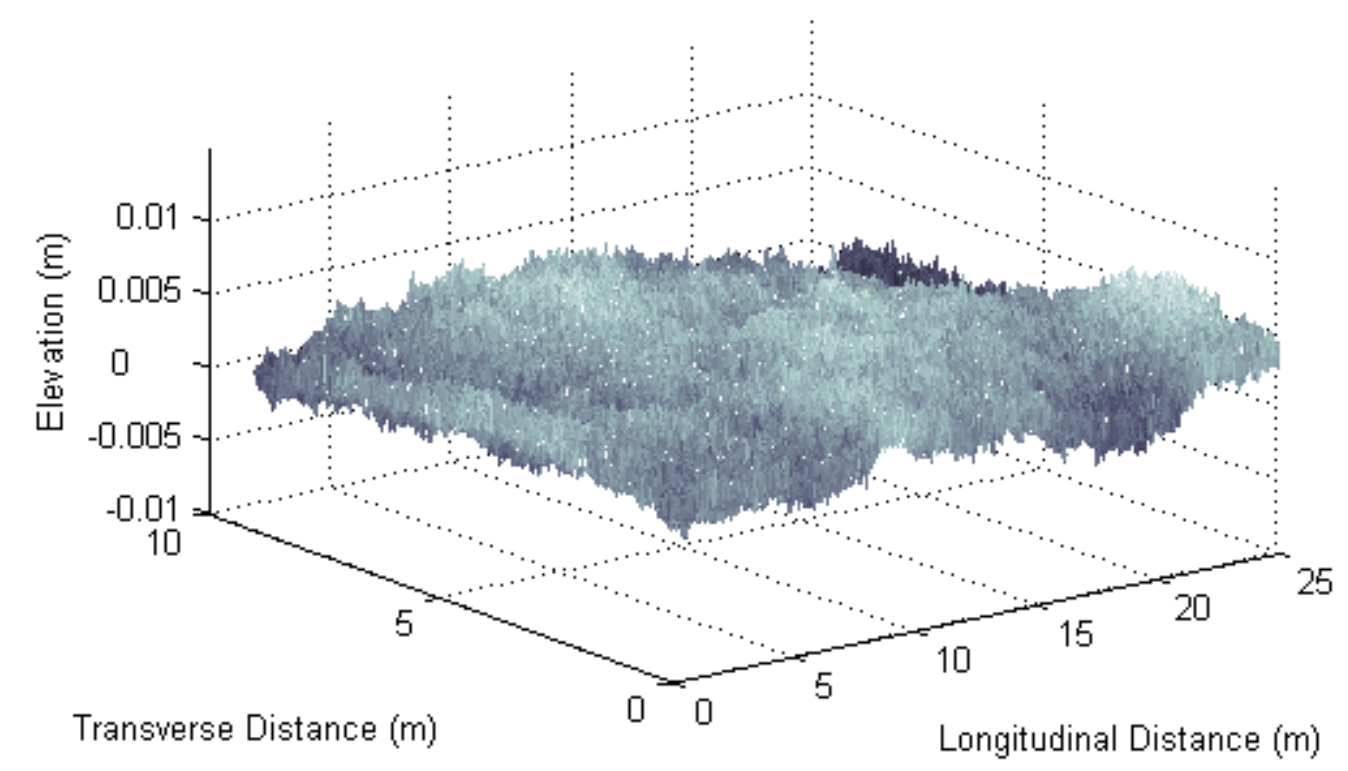

Figure 3. Section of road profile carpet on bridge. 

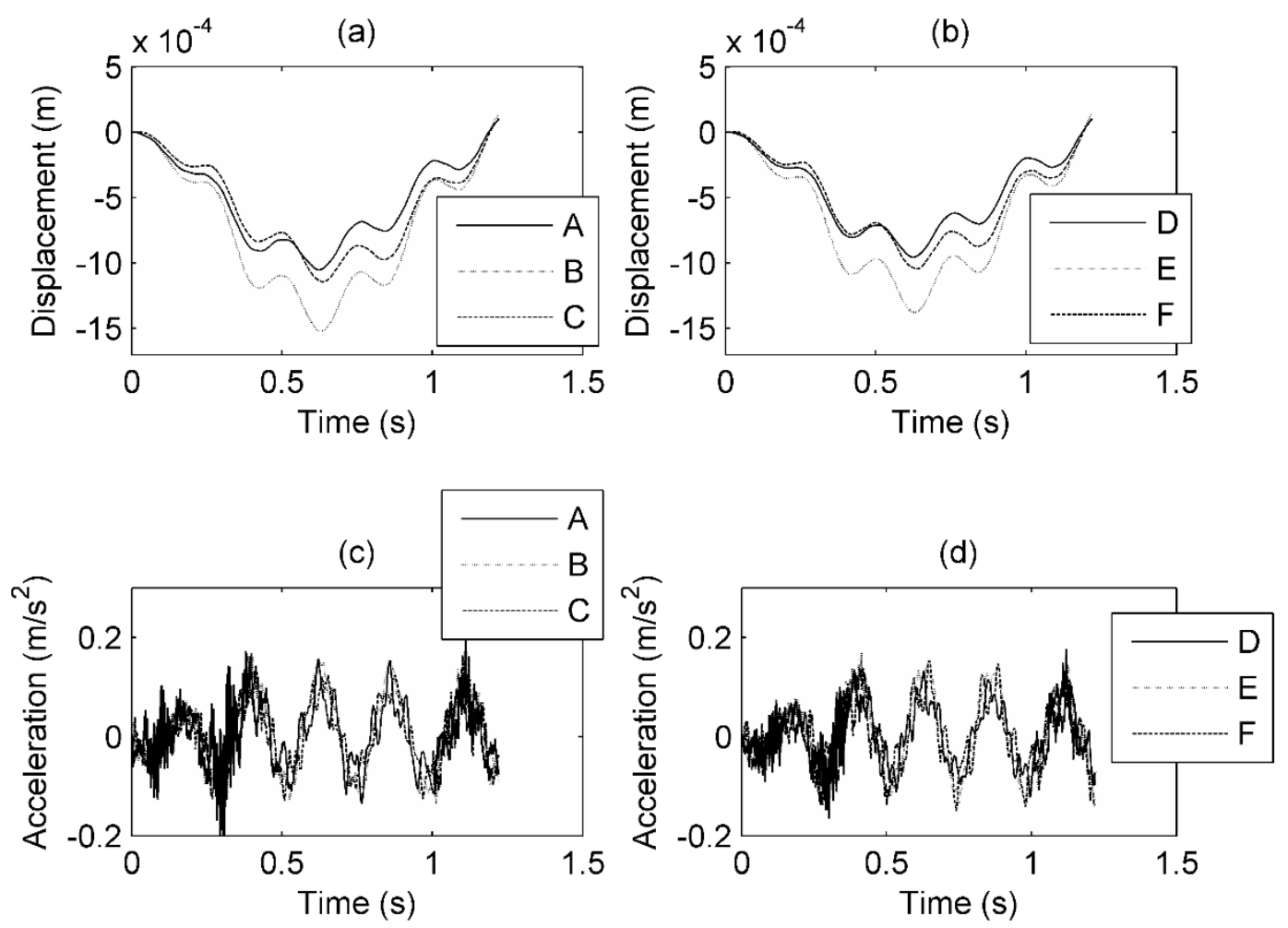

(e)
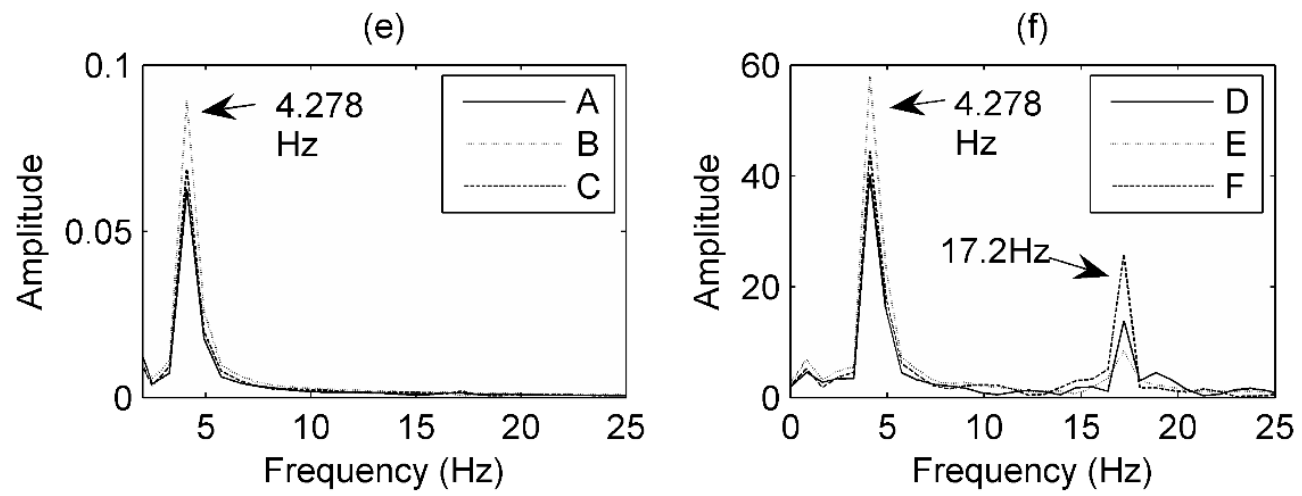

Figure 4. Bridge response when the vehicle traverses the bridge in lane 1 at $25 \mathrm{~m} / \mathrm{s}$ when there is 'part-through' damage in the bridge, (a) Displacements at bridge locations in lane 1, (b) Displacements at bridge locations in lane 2, (c) Accelerations at bridge locations in lane 1, (d) Accelerations at bridge locations in lane 2, (e) Frequency content of displacement signals observed in lane 1, (f) Frequency content of acceleration signals observed in lane 2. 


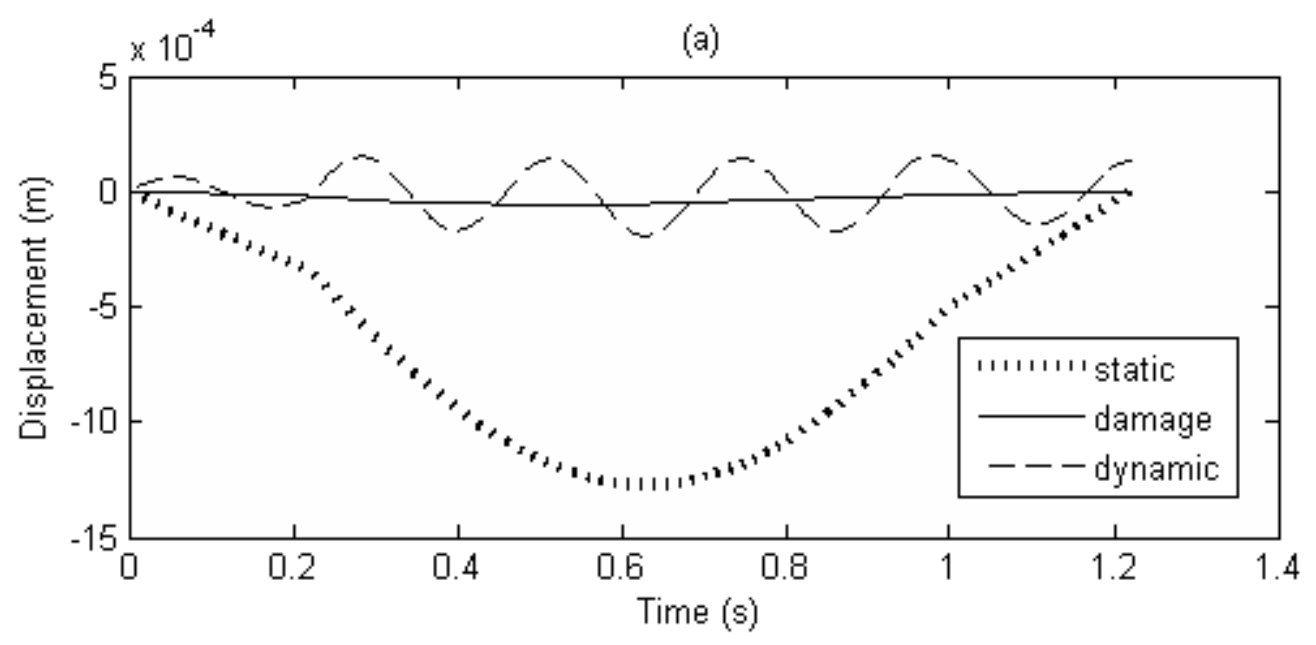

(b)

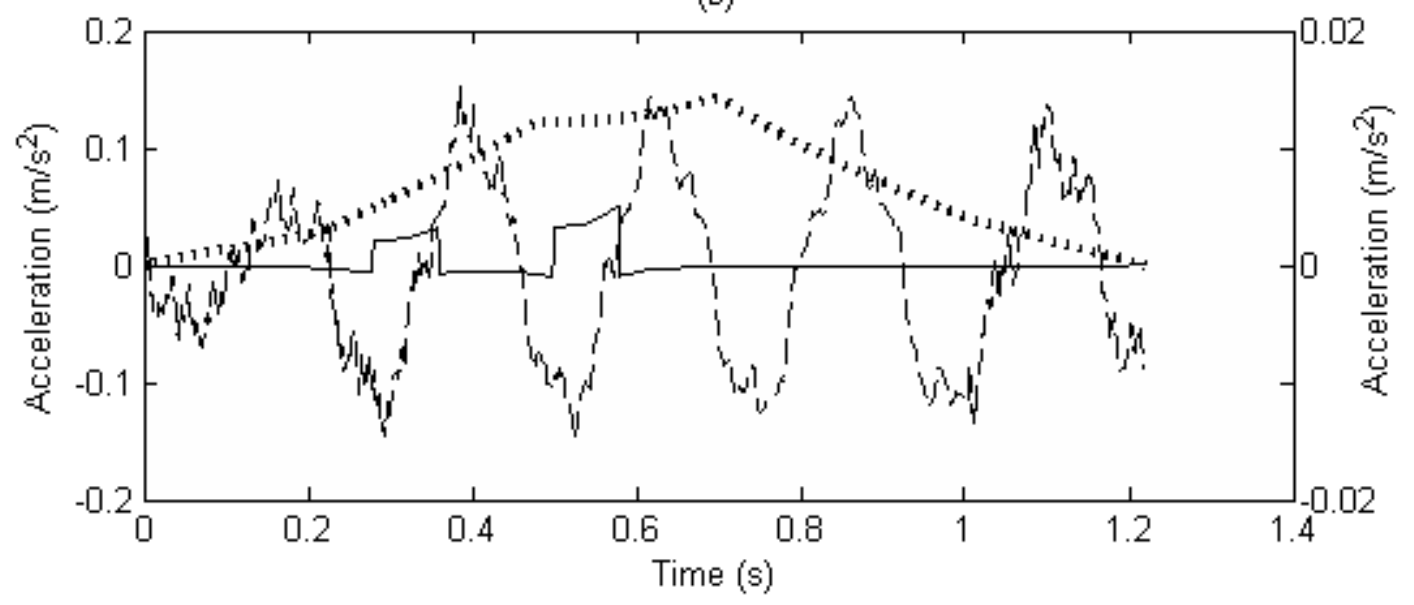

Figure 5. 'dynamic', 'static' and 'damage' components of the response at bridge location B due to a moving vehicle: (a) displacement (b) acceleration. 
(a)

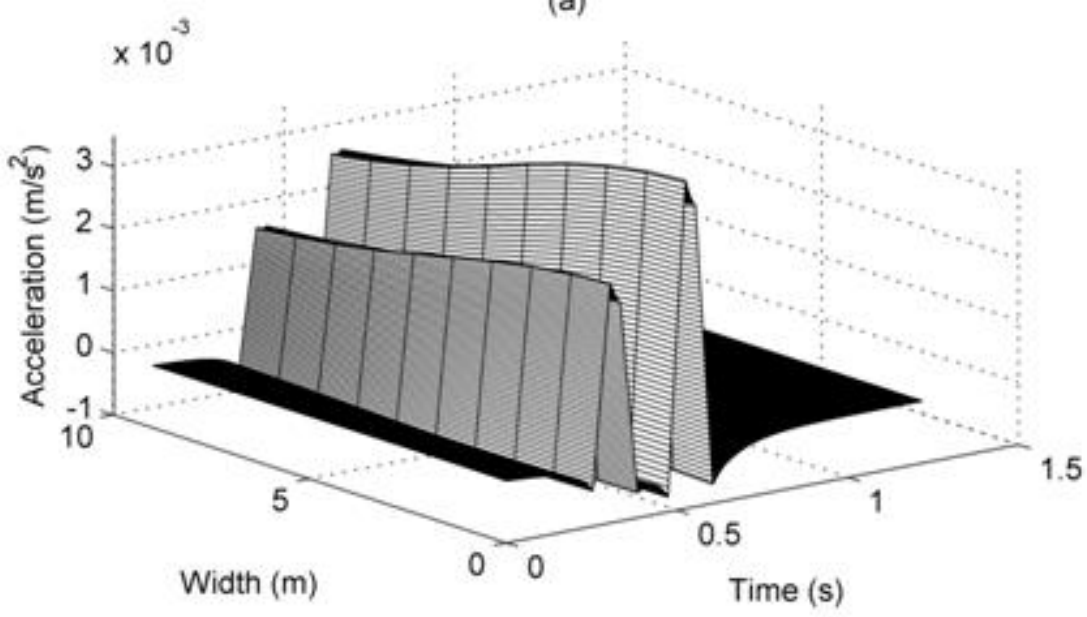

(b)

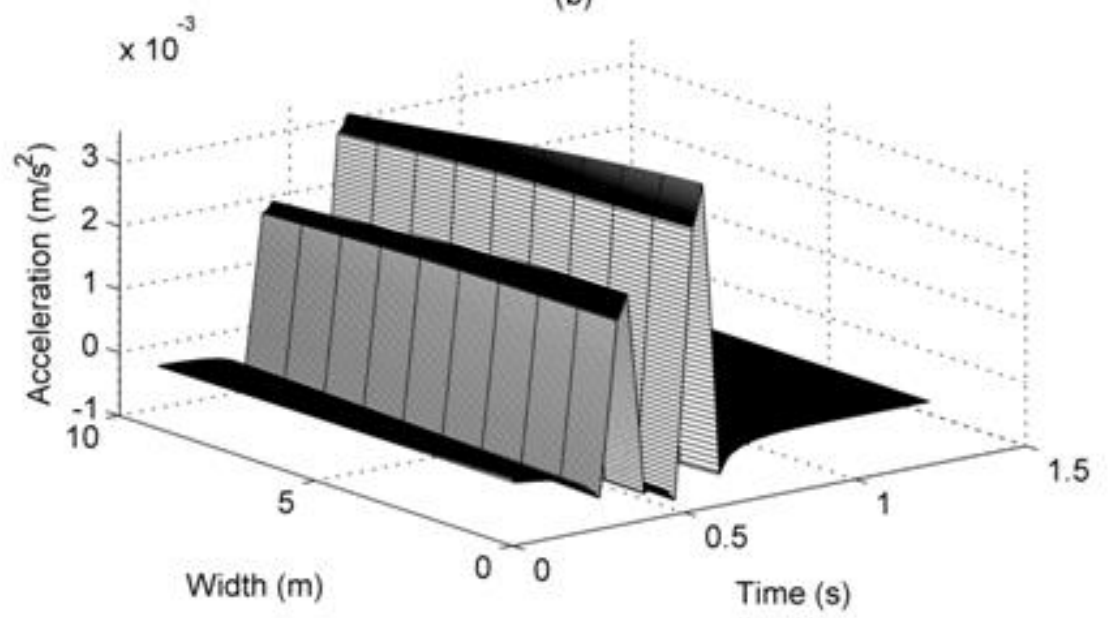

(c)

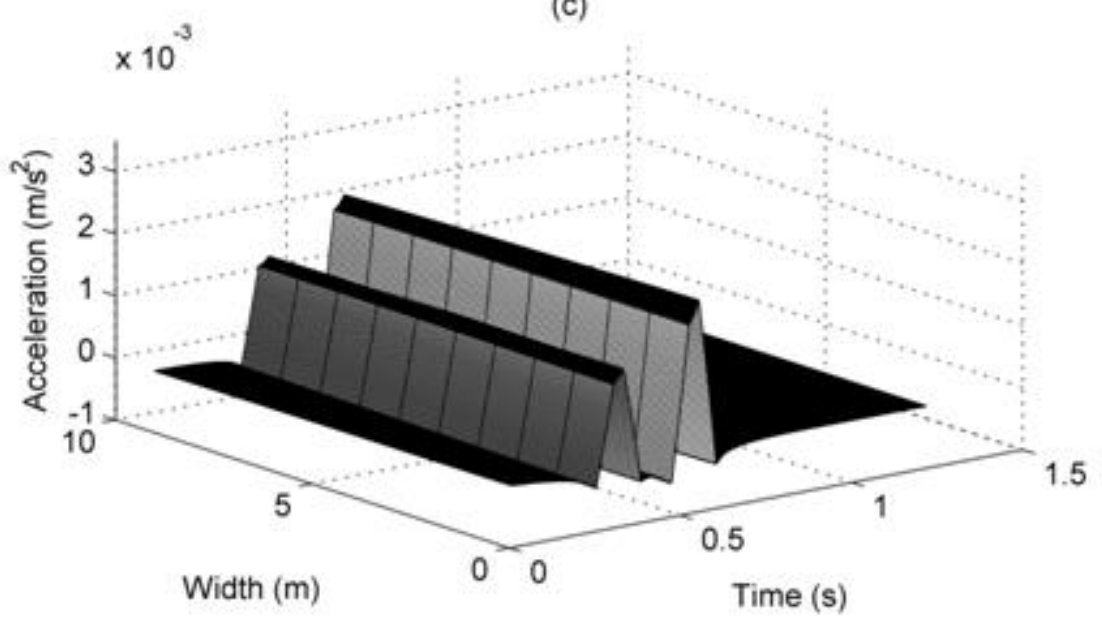

Figure 6. 'Damage' components for different longitudinal cross-sections: (a) 1/4 span, (b) midspan, (c) 3/4 span. 


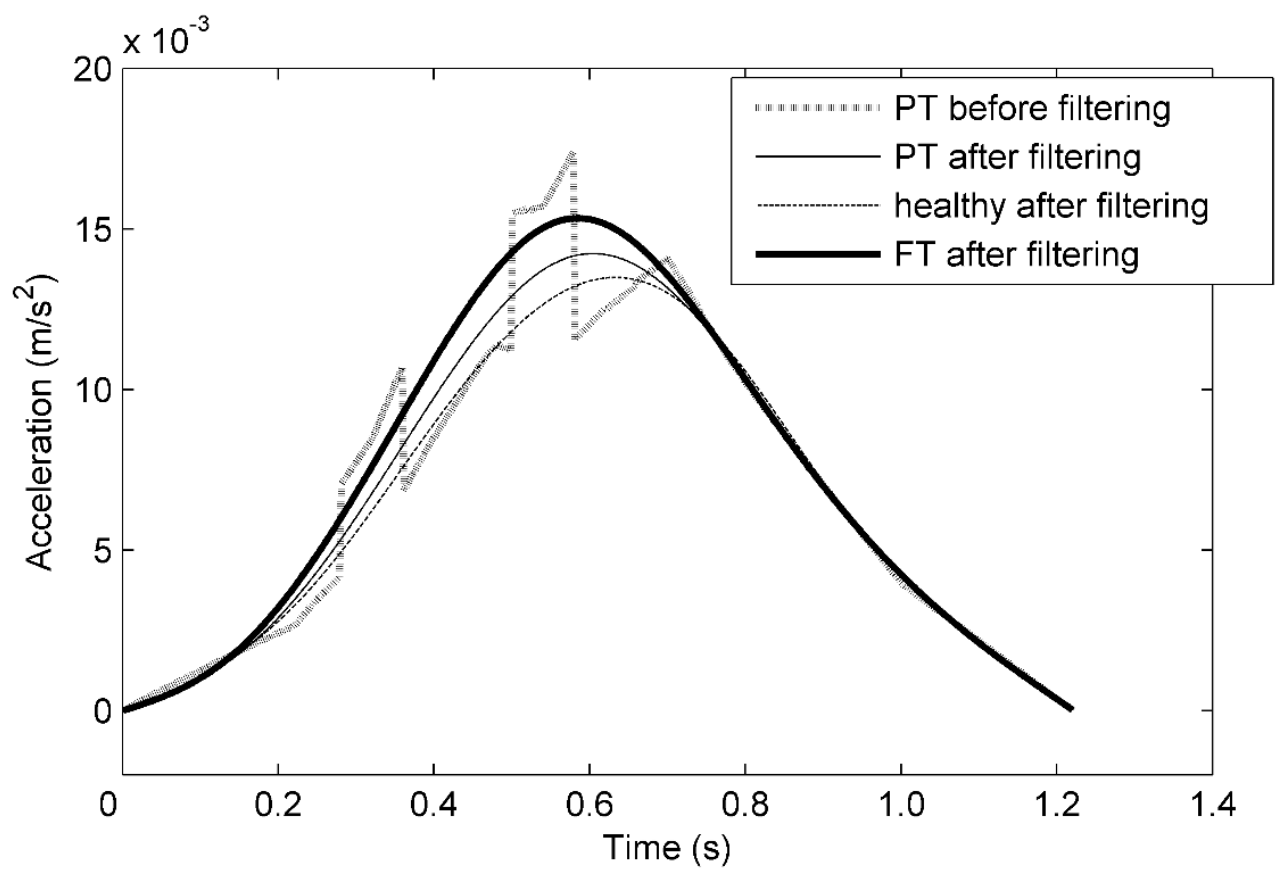

Figure 7. Effect of filtering on theoretical 'static' and 'damage' components. 
(a)
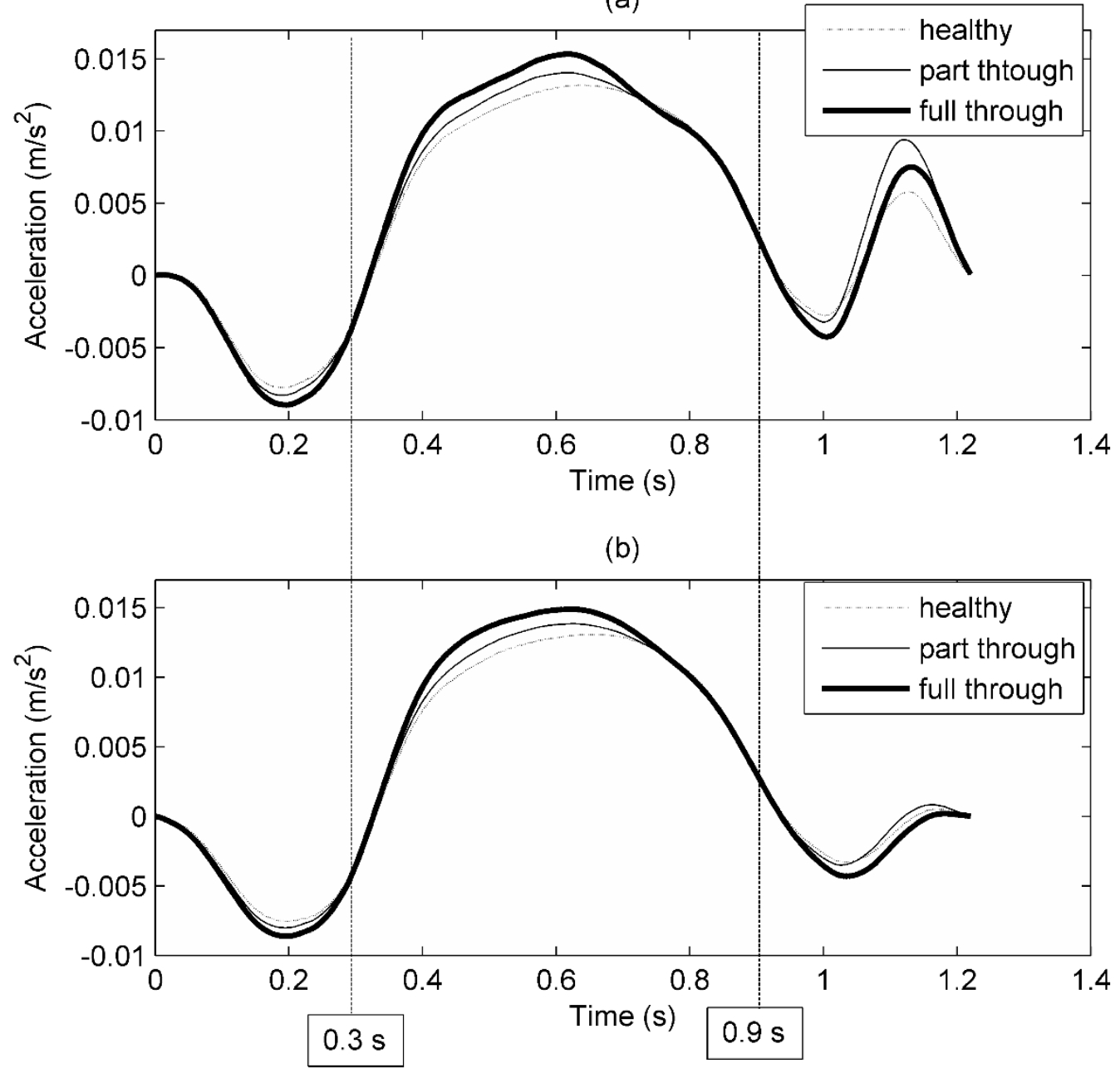

Figure 8. Filtered total acceleration responses, (a) bridge damping ratio $=0 \%$, (b) bridge damping ratio $=5 \%$ 
(a)

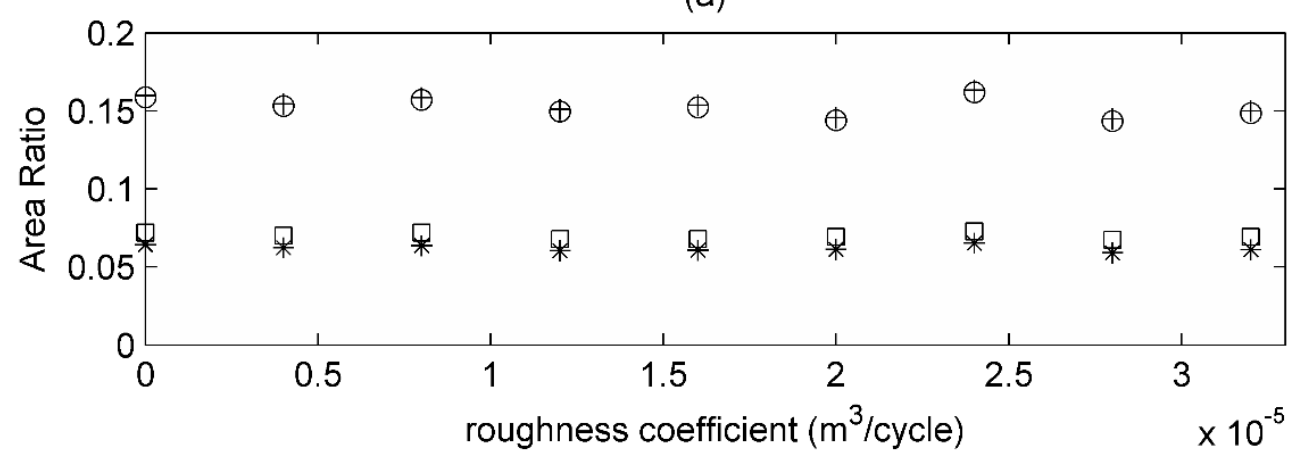

(b)

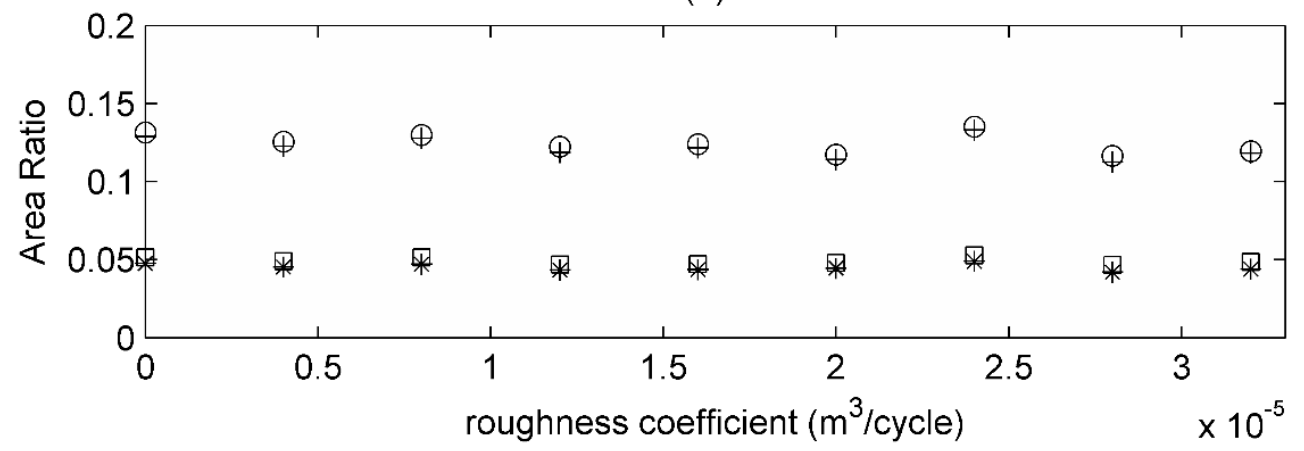

(c)

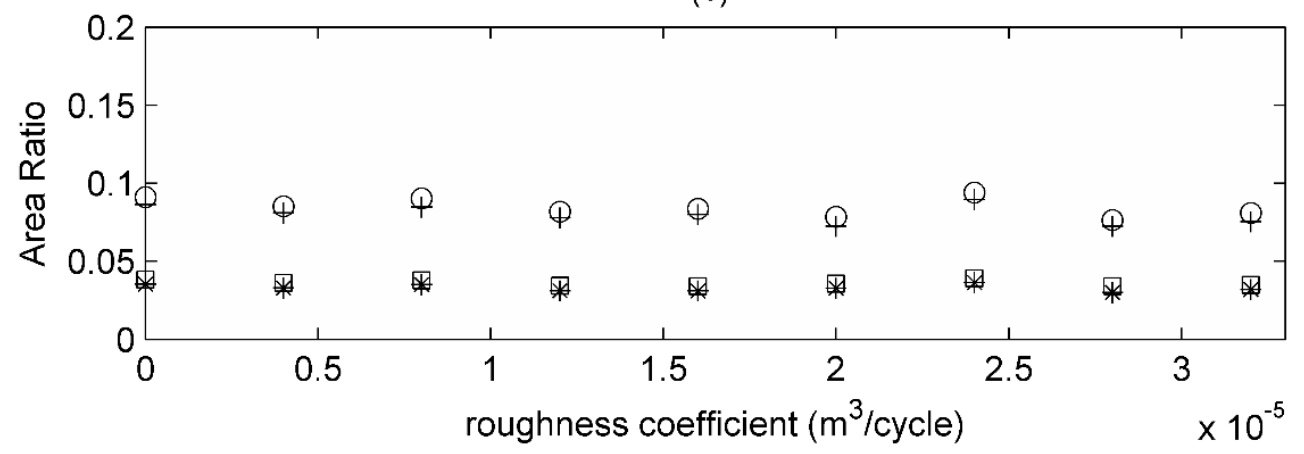

Figure 9. Area ratios for different measurement locations and road profiles: (a) A (lane 1, 1/4 span), (b) E (lane 2, mid-span), (c) C (lane 1, 3/4 span). Damage scenario: $\square$ 'part-through' and vehicle in lane 1, + 'full-through' and vehicle in lane $1, *$ 'part-through' and vehicle in lane 2, o 'full-through' and vehicle in lane 2. 
(a)

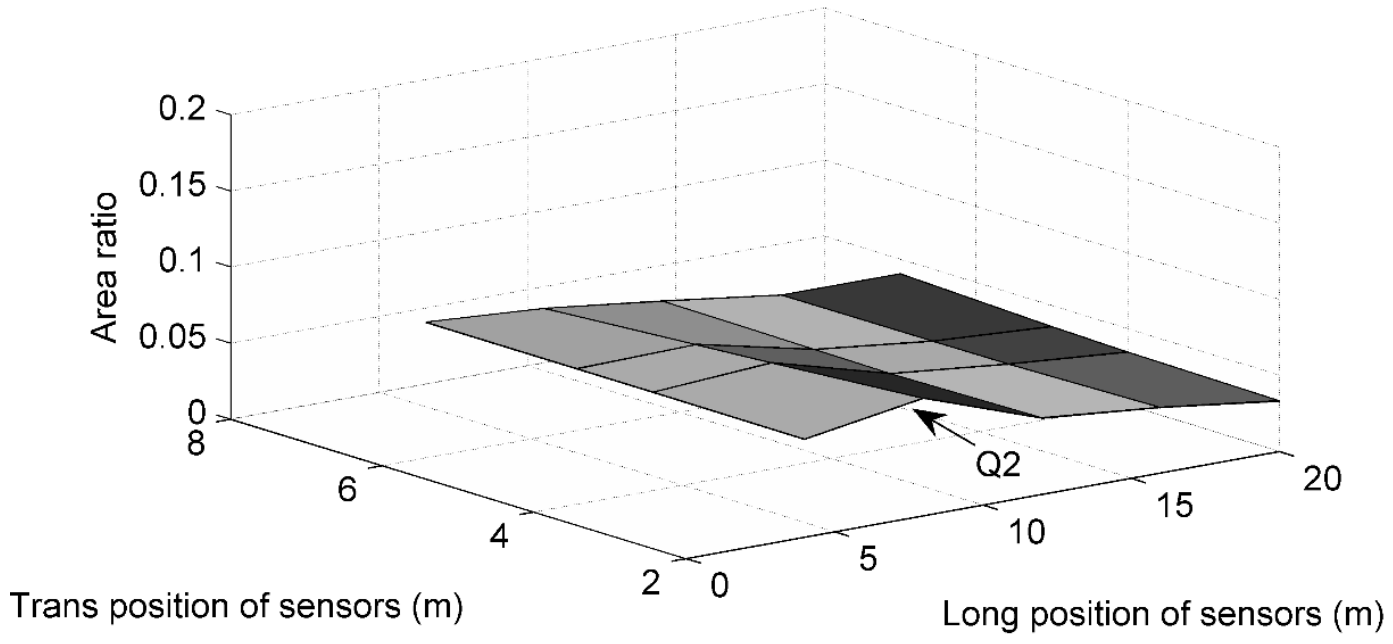

(b)

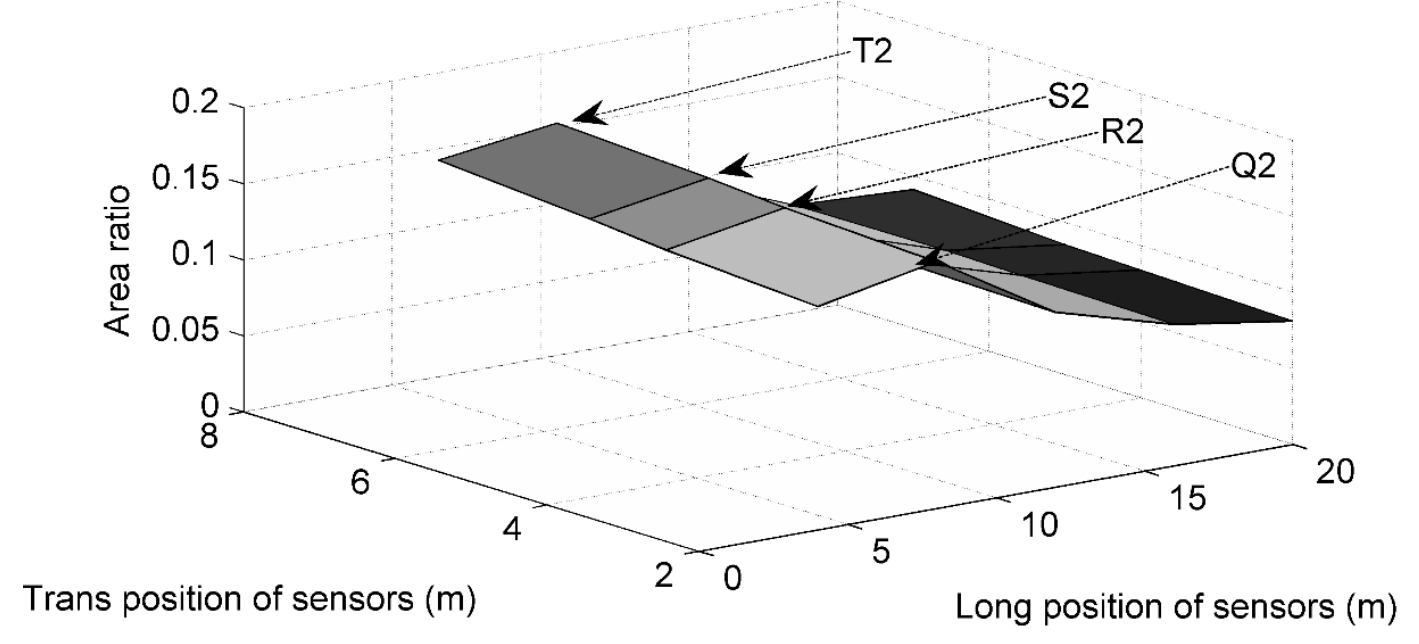

Figure 10. Area ratios observed at 20 bridge locations (Q1-T5) when truck travels in lane 1 for damage scenarios: (a) 'part-through' (50\% stiffness loss), (b) 'full-through' (50\% stiffness loss). 
(a)

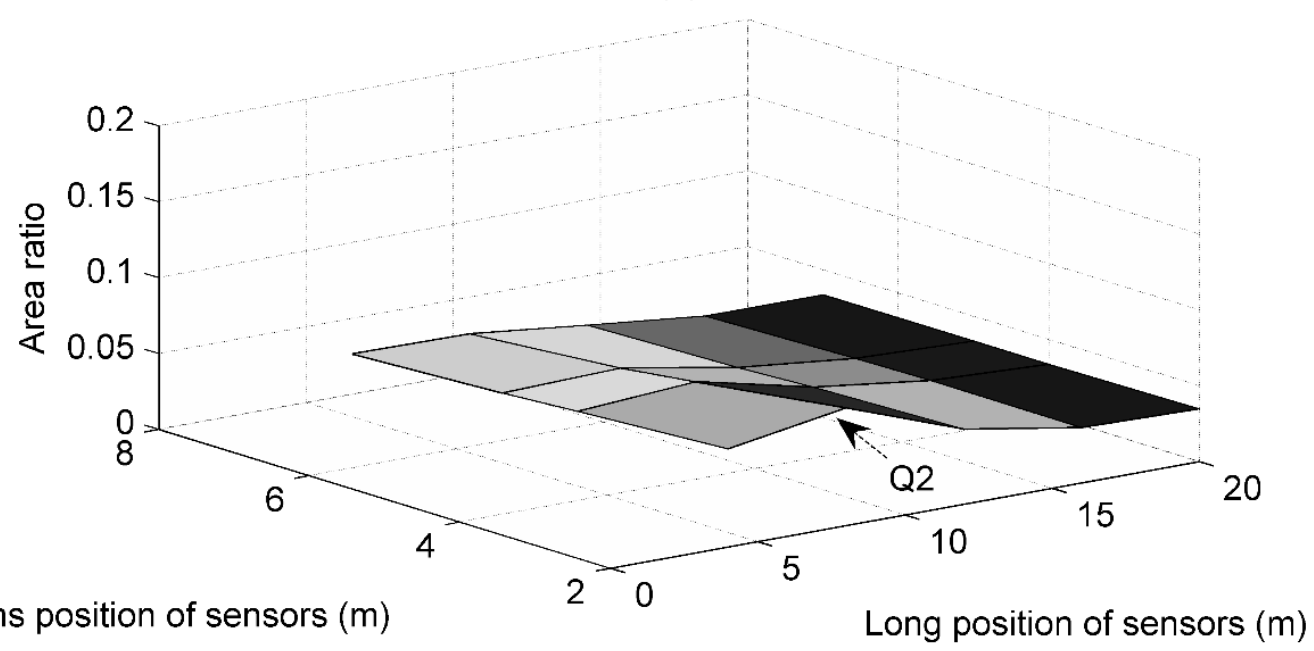

(b)

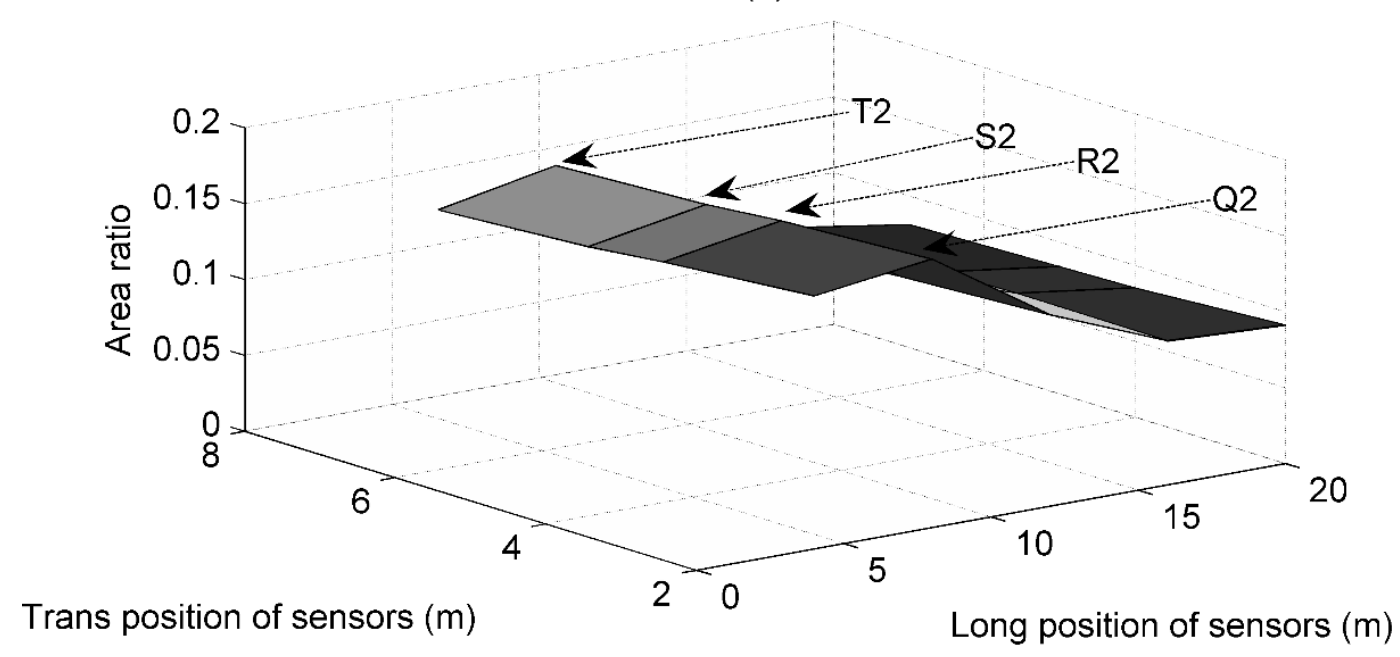

Figure 11. Area ratios observed at 20 bridge locations (Q1-T5) when truck travels in lane 2 for damage scenarios: (a) 'part-through' (50\% stiffness loss), (b) ‘full-through' (50\% stiffness loss). 
(a)

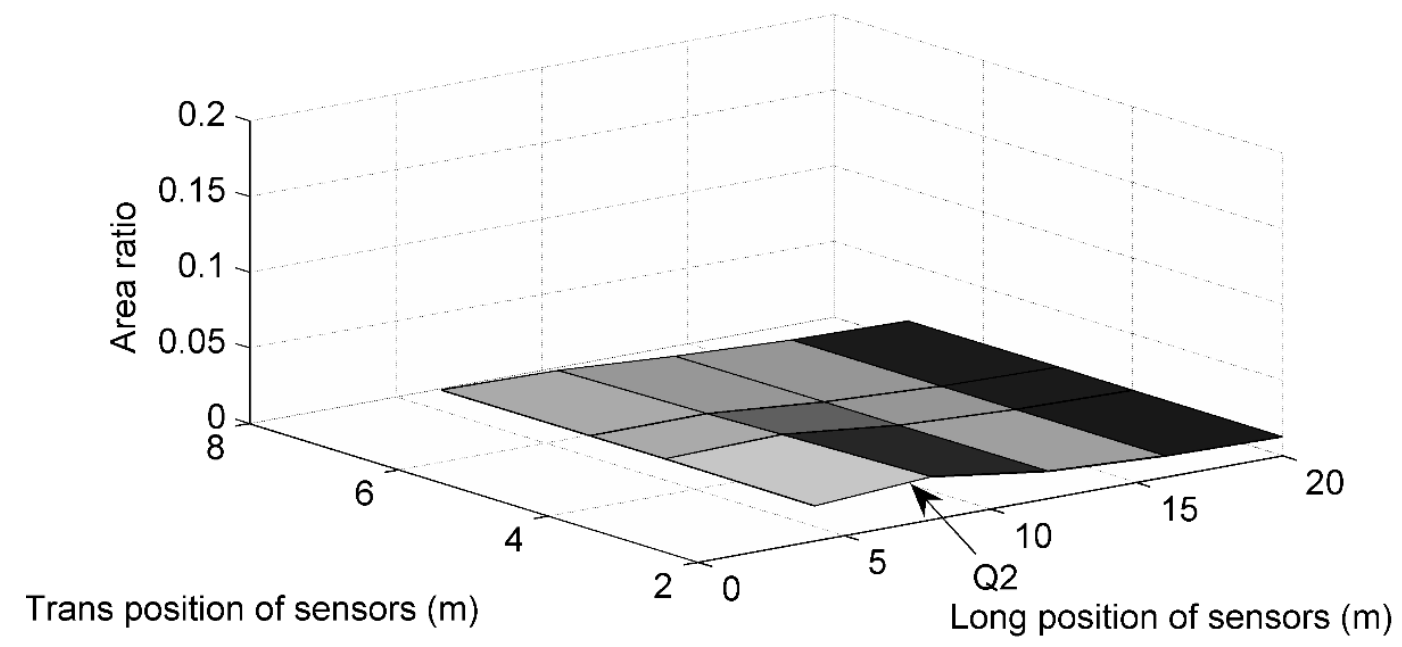

(b)

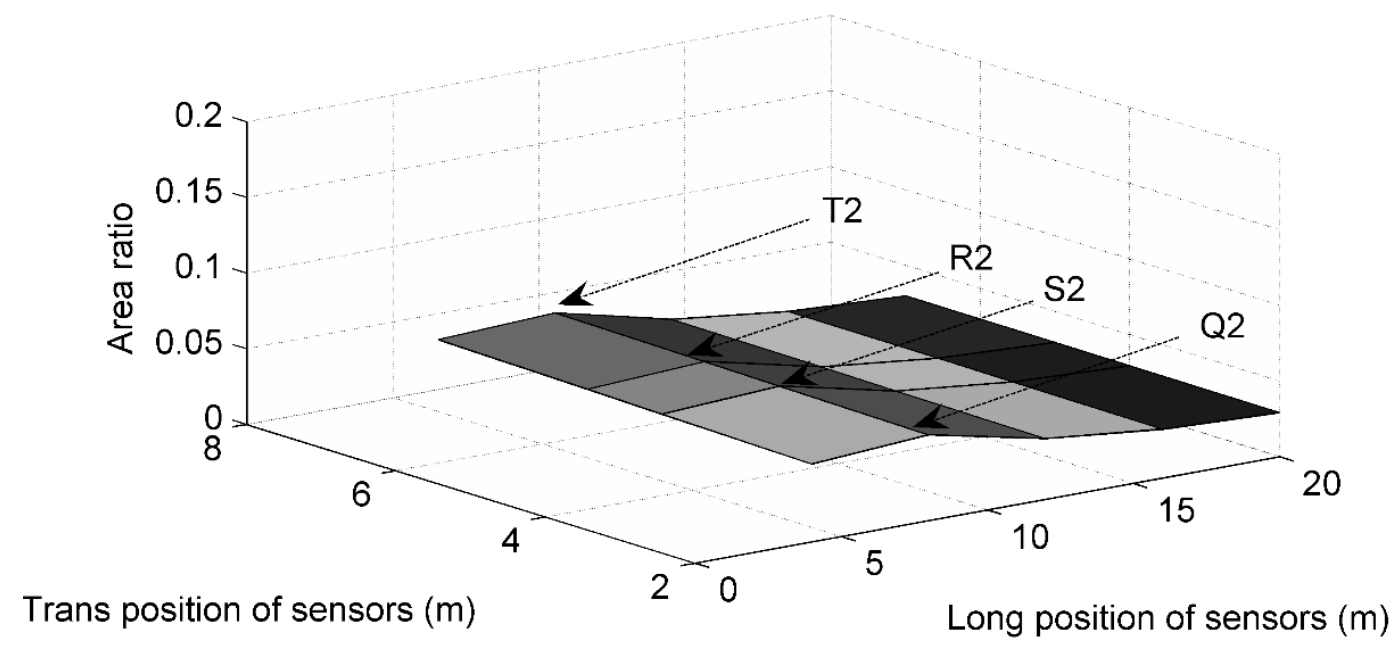

Figure 12. Area ratios observed at 20 bridge locations (Q1-T5) when truck travels in lane 1 for damage scenarios: (a) 'part-through'(25\% stiffness loss), (b) 'full-through'(25\% stiffness loss). 


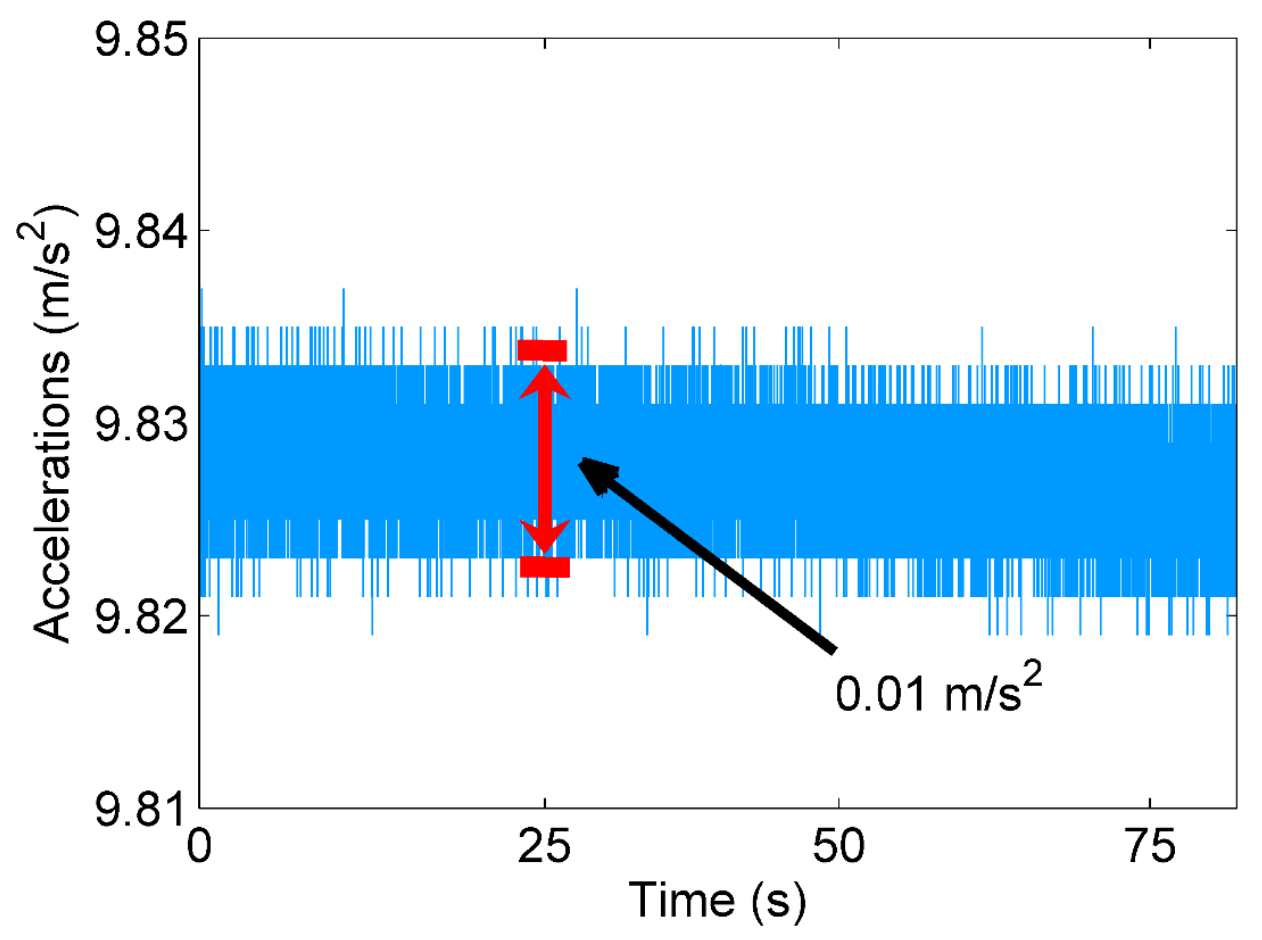

Figure 13. Acceleration signal measured using an at rest QA700 accelerometer. 
(a)

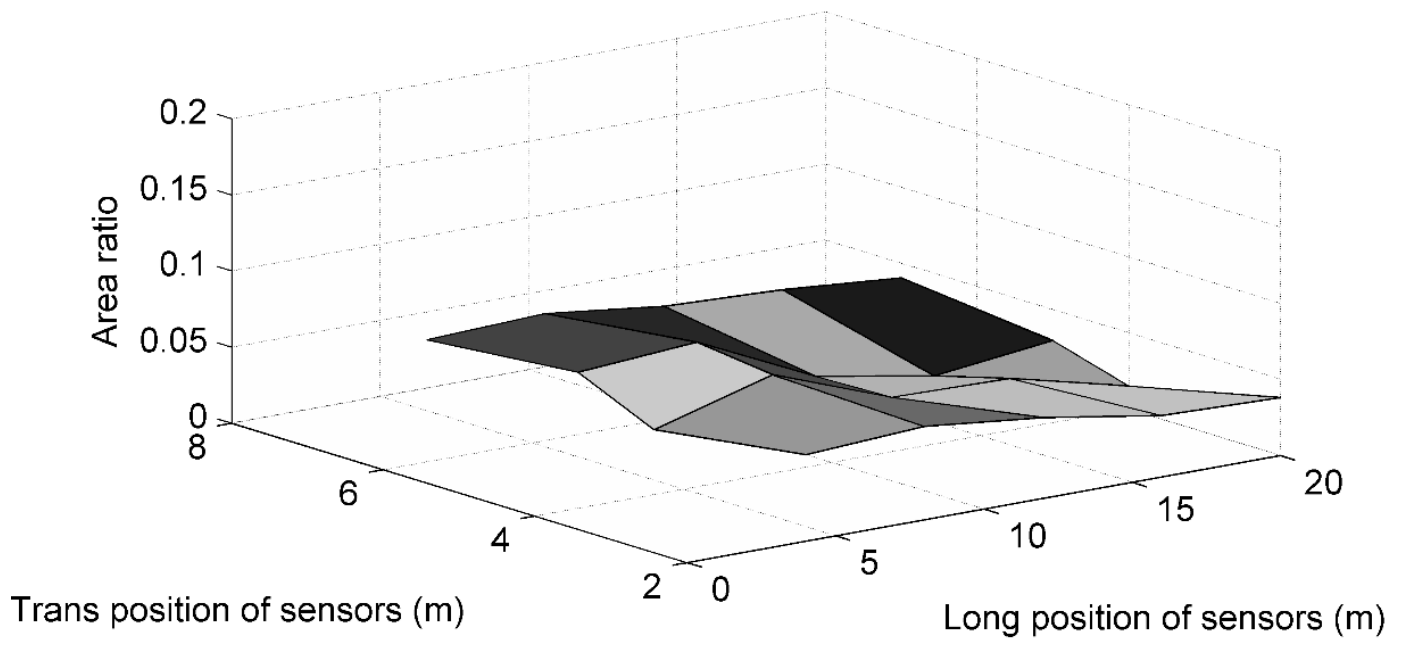

(b)

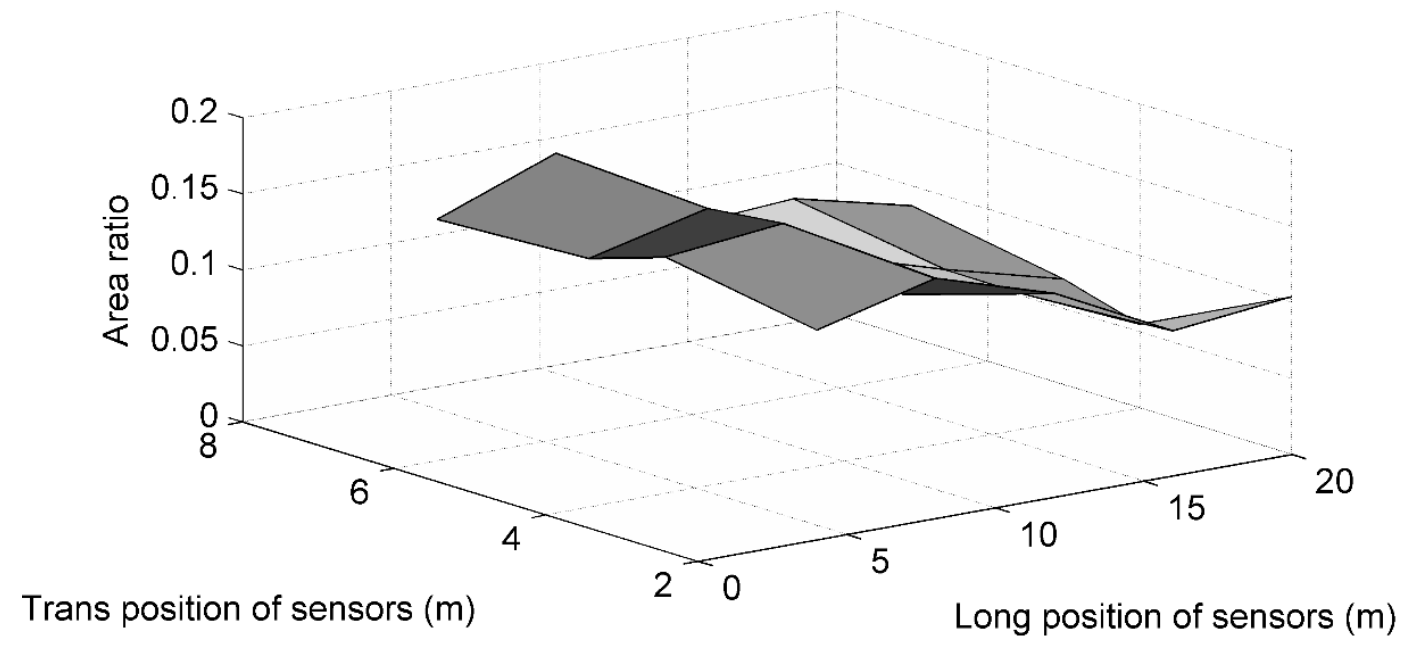

Figure 14. Area ratios observed at 20 bridge locations when acceleration contains $3 \%$ noise and truck travels in lane 1 for damage scenarios: (a) 'part-through'(50\% stiffness loss), (b) 'full-through' (50\% stiffness loss). 
(a)

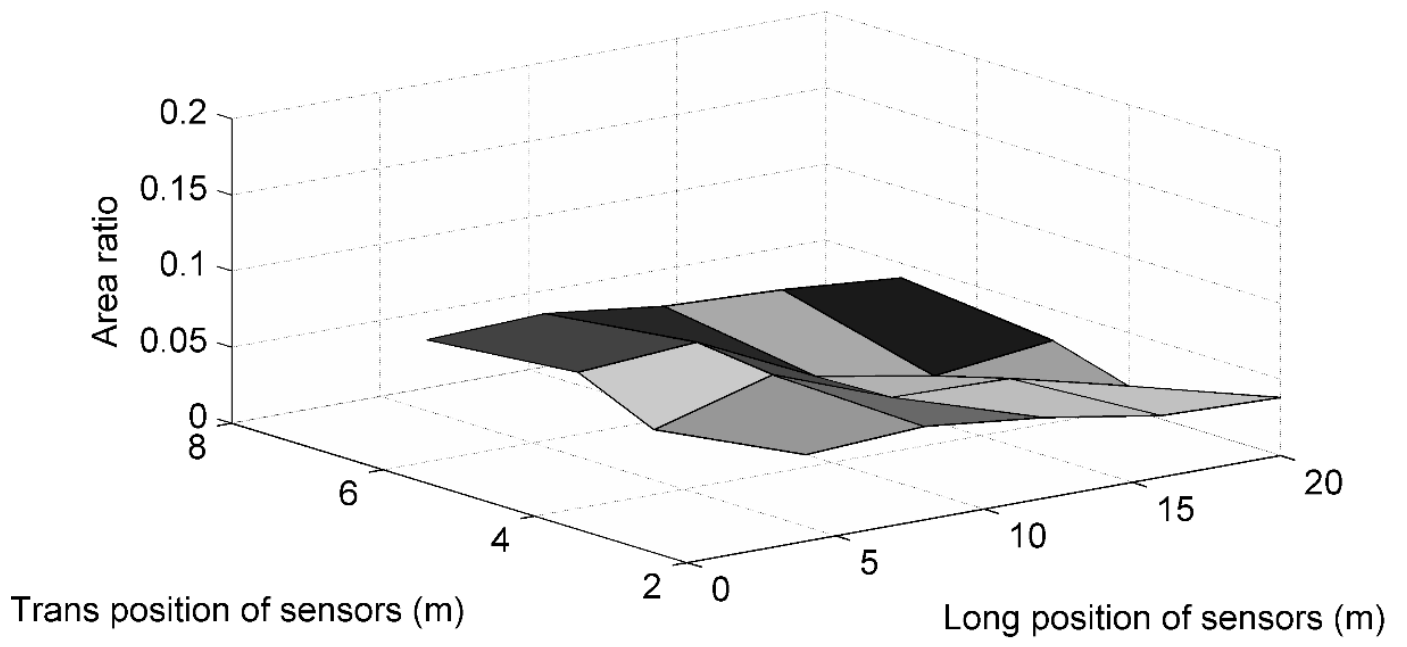

(b)

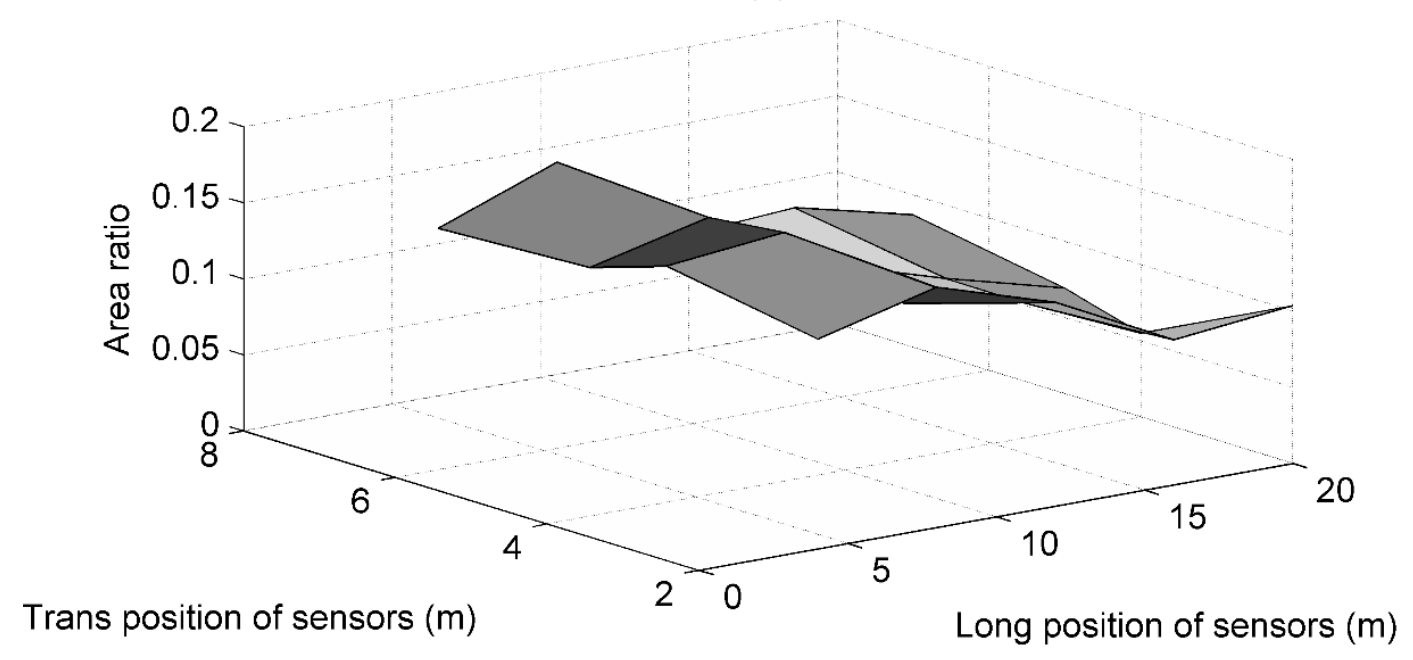

Figure 15. Area ratios observed at 20 bridge locations when acceleration contains $3 \%$ noise and truck travels in lane 2 for damage scenarios: (a) 'part-through'(50\% stiffness loss), (b) 'full-through' (50\% stiffness loss). 


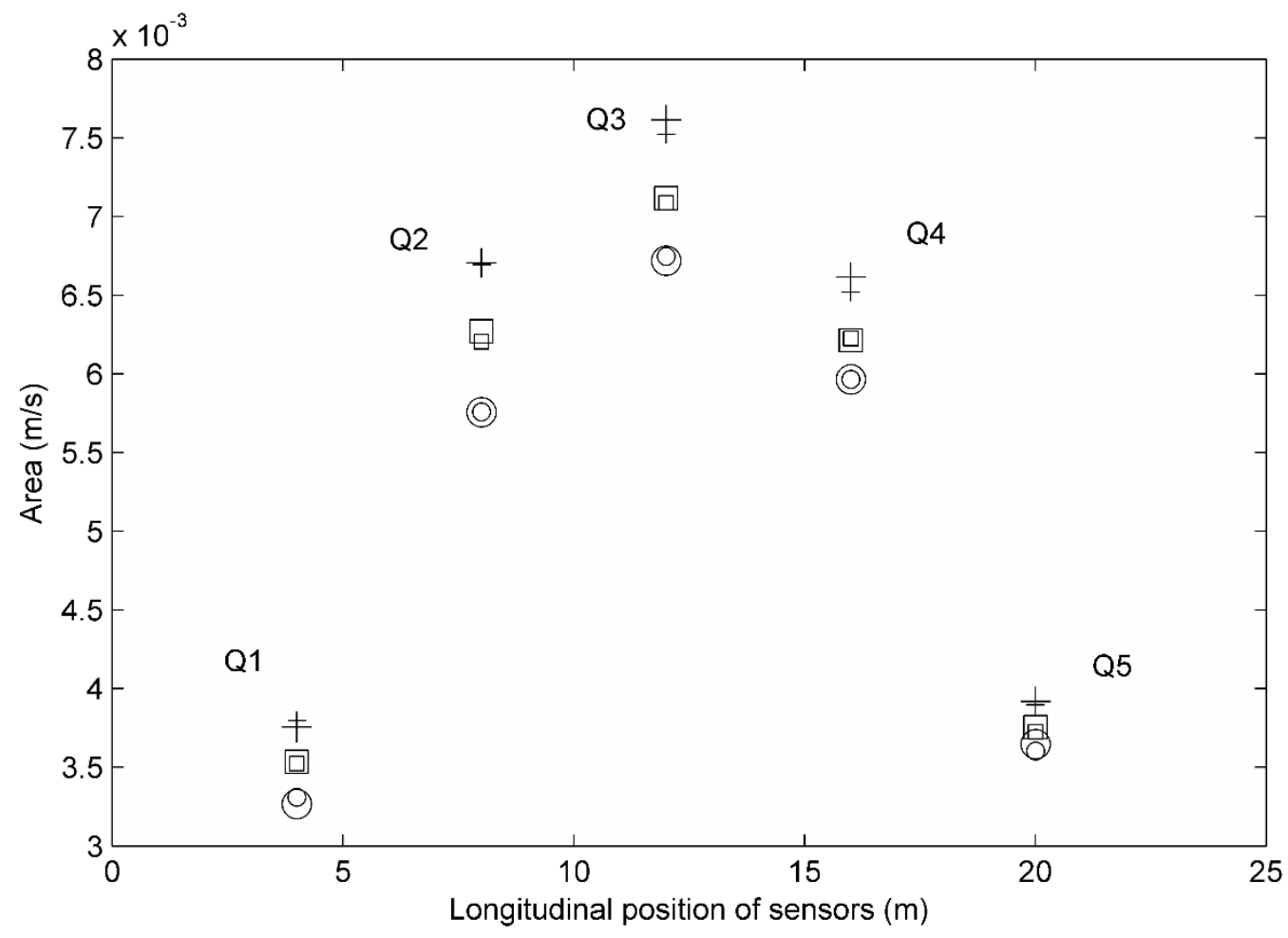

Figure 16. Variation in area with noise at sensor locations Q1 (lane 1, 0.16 span), Q2 (lane 1, 0.32 span), Q3 (lane 1, 0.48 span), Q4 (lane 1, 0.64 span) and Q5 (lane 1, 0.8 span). Damage scenarios: O Healthy, $\square$ 'part-through', + 'full-through'; Noise level: small and large symbols refer to $0 \%$ and $3 \%$ noise respectively. 


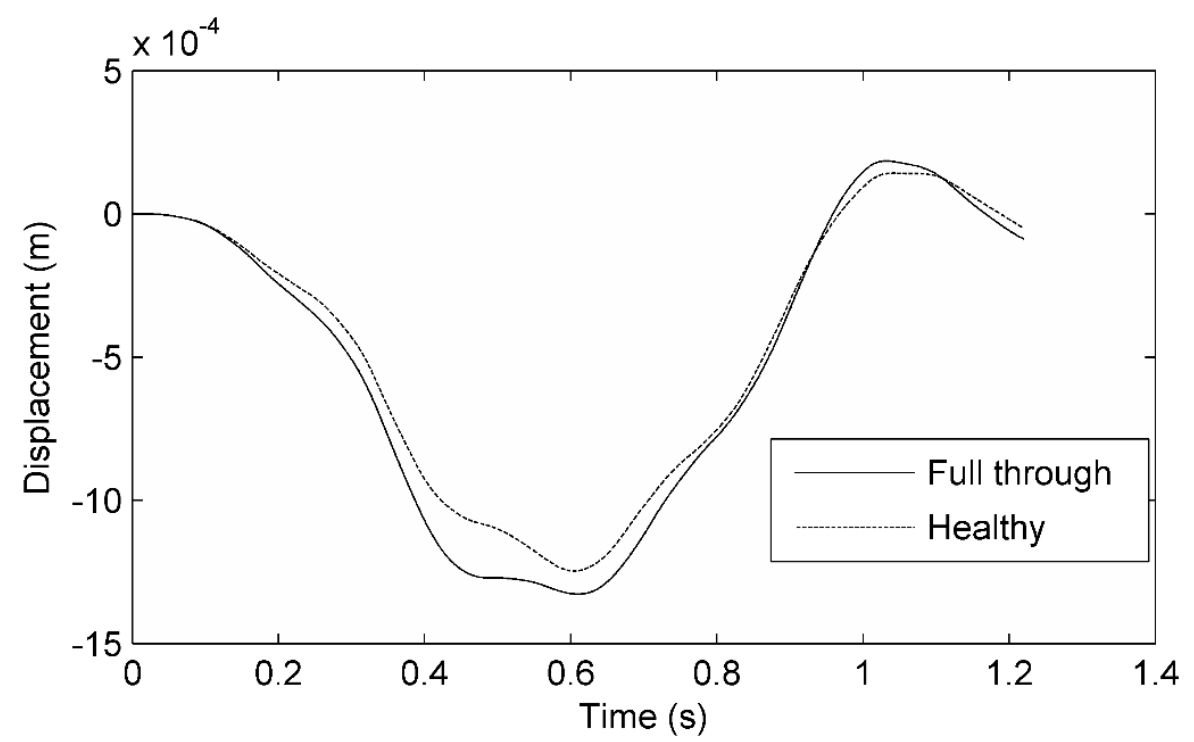

Figure 17. Displacement of wheel 1 on the front axle for the healthy and 'full-through' scenarios.

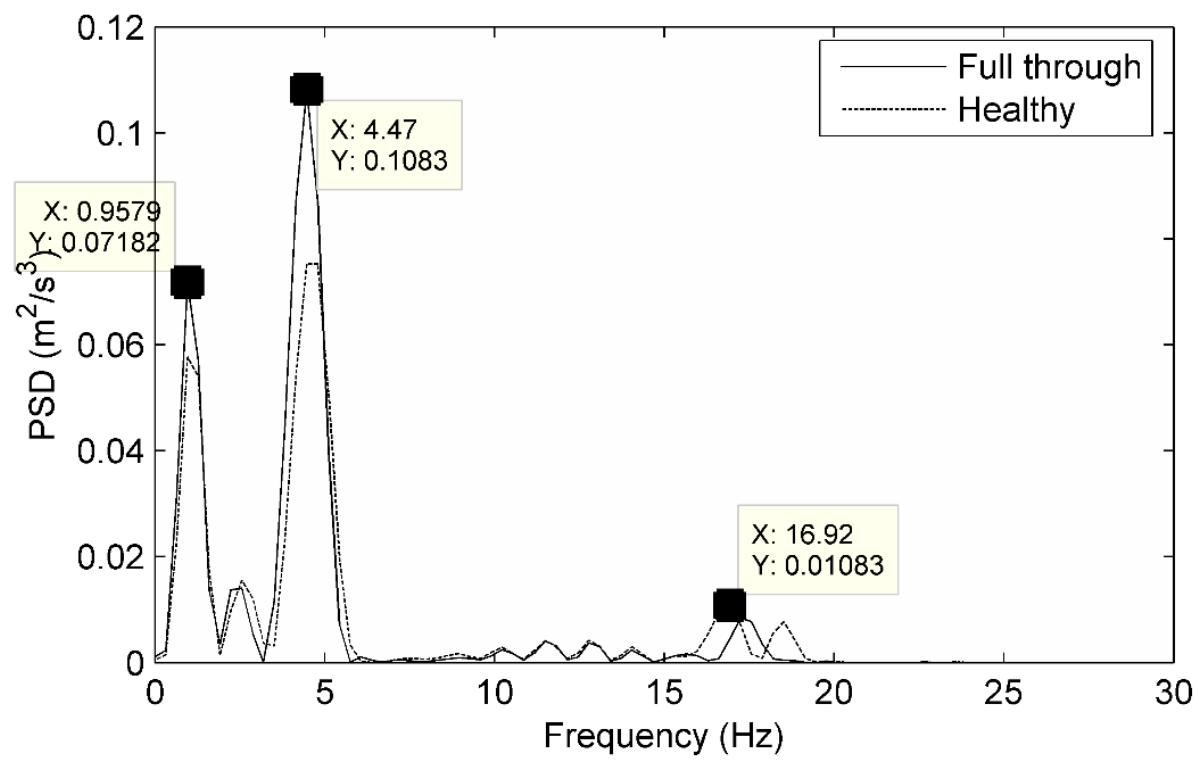

Figure 18. Frequency content of accelerations shown in Figure 17. 
(a)
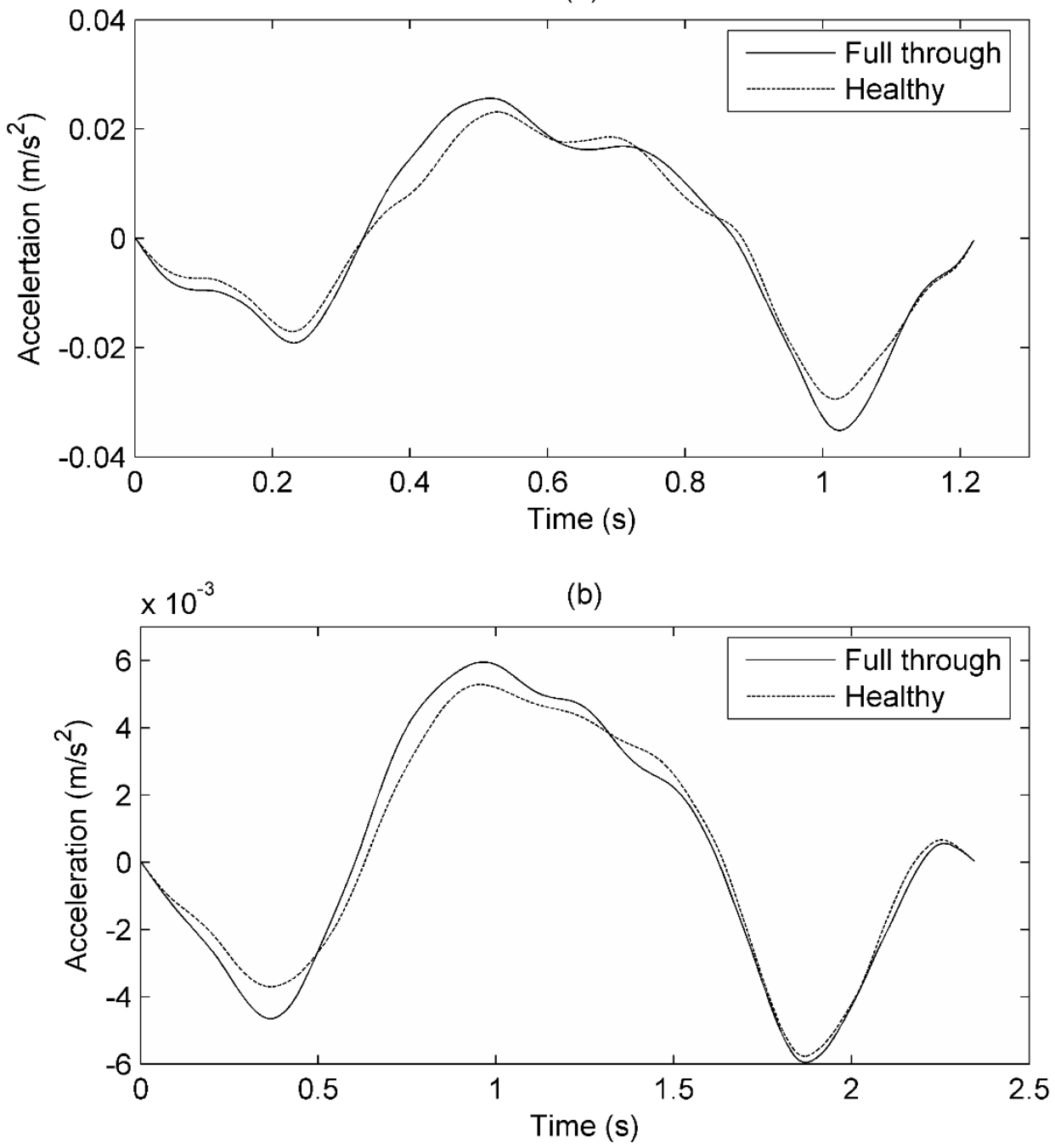

Figure 19. Effect of removing bridge frequencies from front wheel accelerations for vehicle speeds of: (a) $25 \mathrm{~m} / \mathrm{s}$ (b) $13 \mathrm{~m} / \mathrm{s}$. 

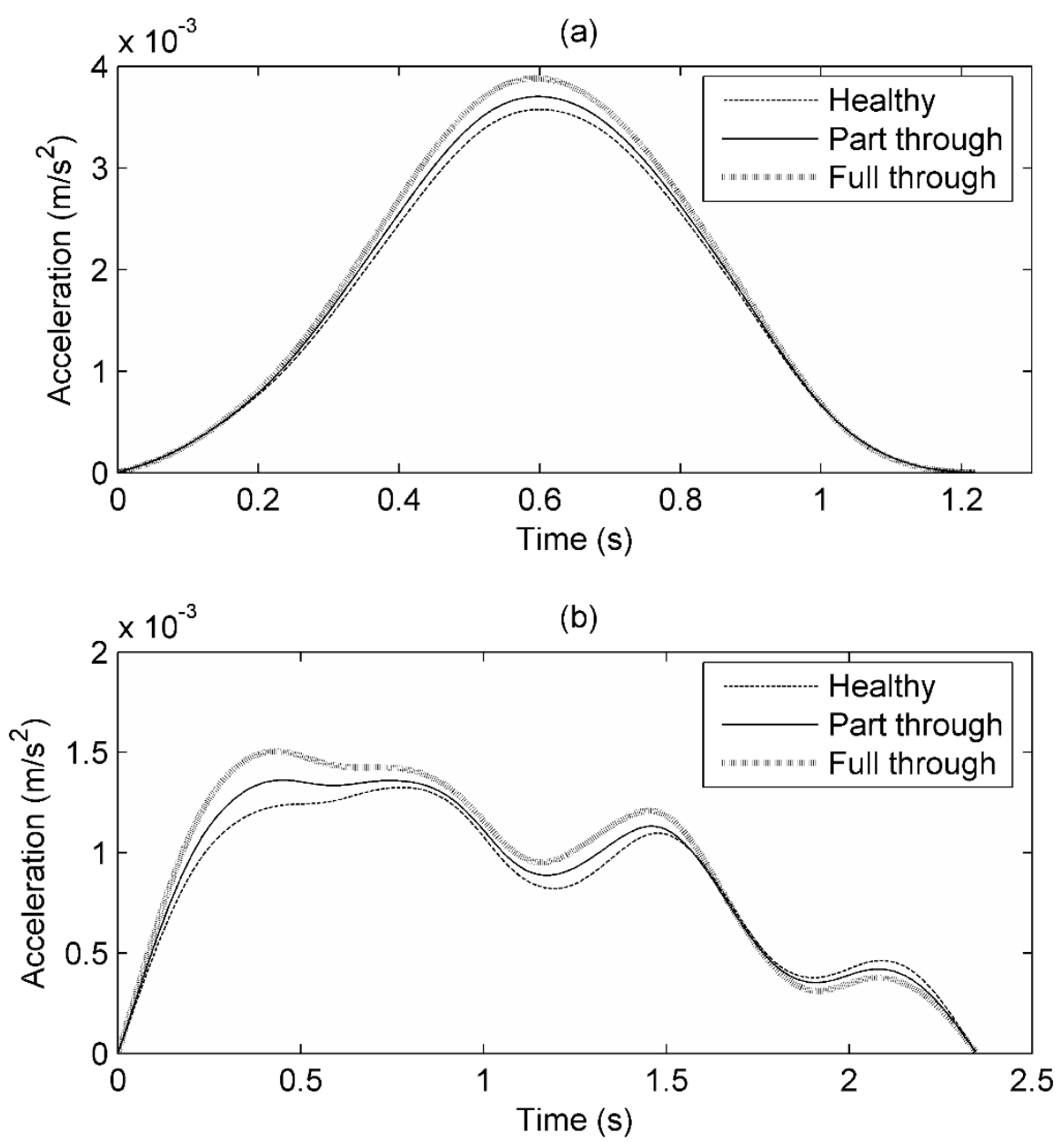

Figure 20. Effect of filtering the acceleration of wheel 1 acceleration signals for different damage scenarios: (a) $25 \mathrm{~m} / \mathrm{s}$, (b) $13 \mathrm{~m} / \mathrm{s}$. 

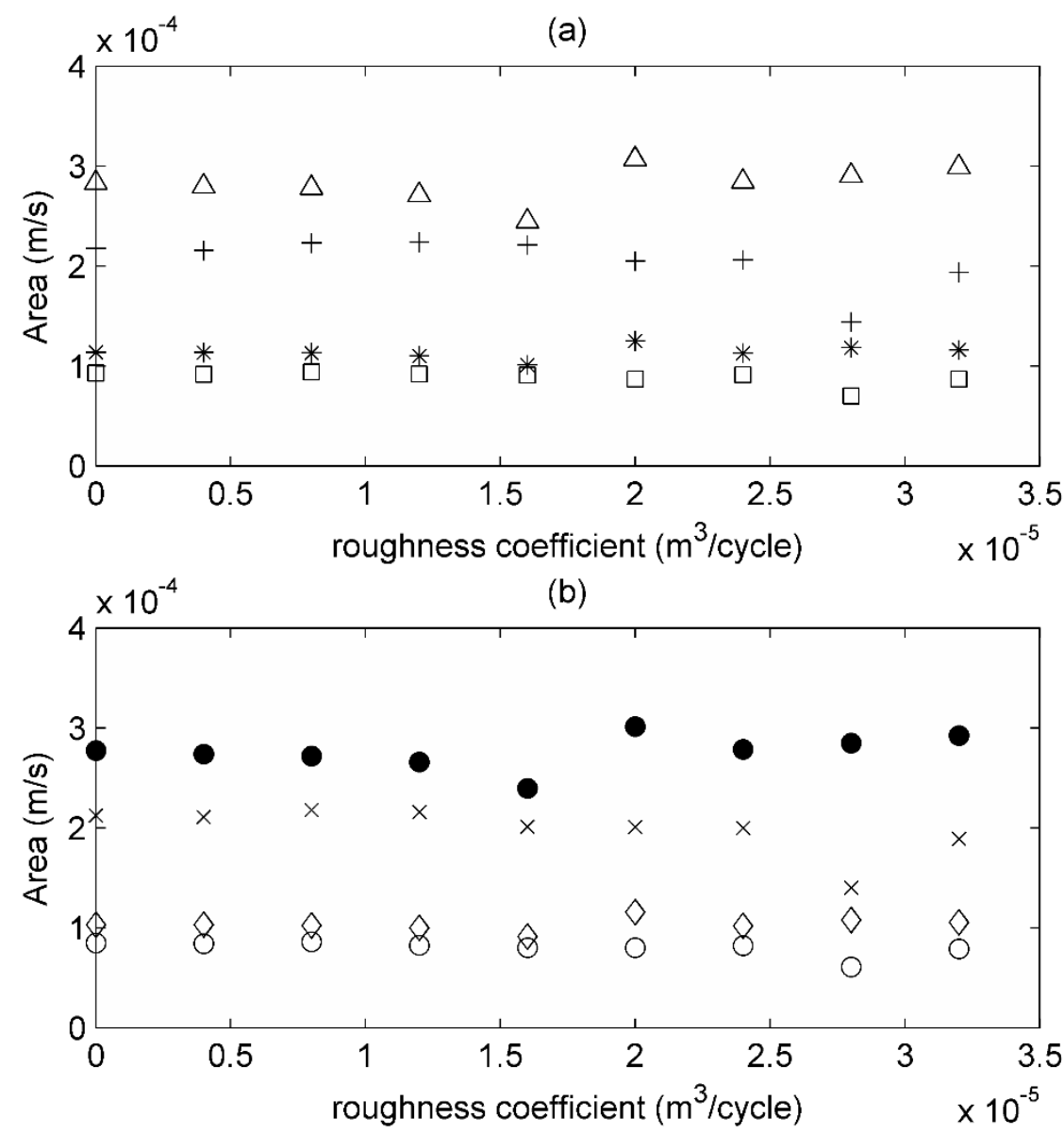

Figure 21. Area between healthy and damaged wheel accelerations for a range of road surfaces, (a) wheels on right hand side of vehicle (W1 and W2 in Figure 1), (b) wheels on left hand side of vehicle (W3 and W4 in Figure 1). Legend: $\square$ 'part-through' and W1, + 'fullthrough' and W1, * 'part-through' and W2, $\Delta$ 'full-through' and W2, o 'part-through' and W3, x 'full-through' and W3, $\diamond$ 'part-through' and W4, • 'full-through' and W4. 


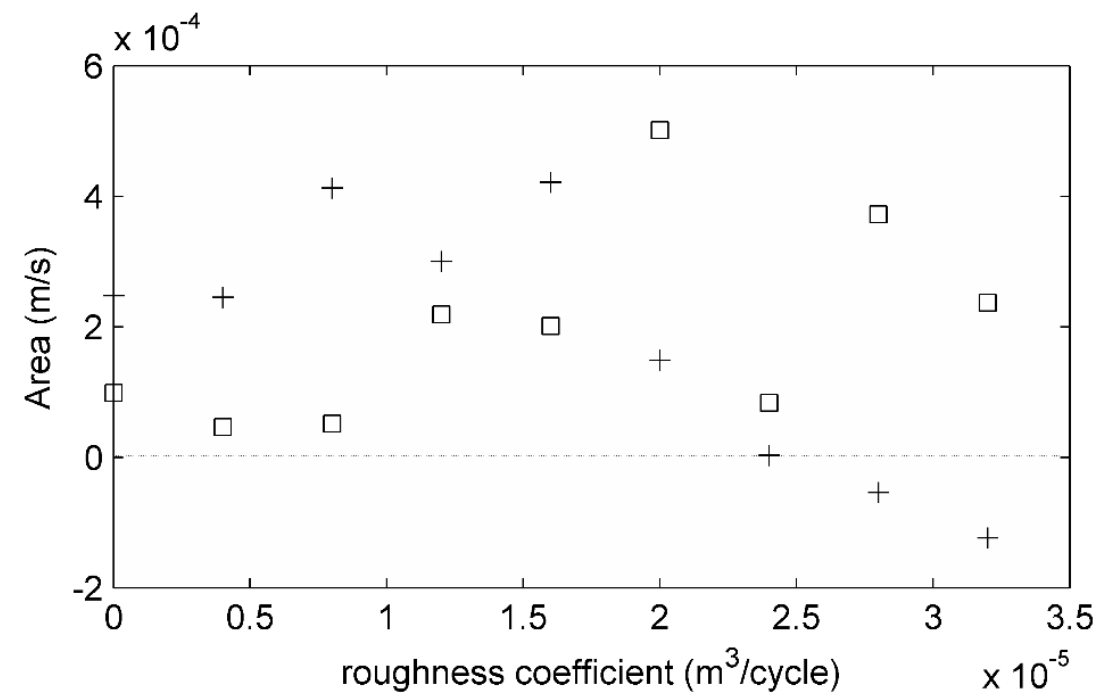

Figure 22. Area between healthy and damaged wheel accelerations for a range of road surfaces when $1 \%$ noise added to the signals. Legend: $\square$ 'part-through', + 'full-through'. 